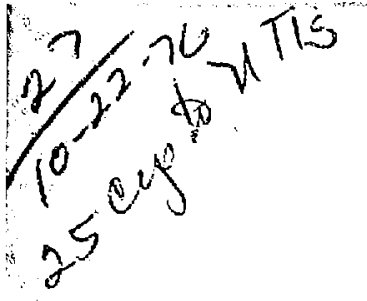

\title{
SYNCHROTRON RADIATION RESEARCH FACILITY
}

\section{CONCEPTUAL. DESIGN REPORT}

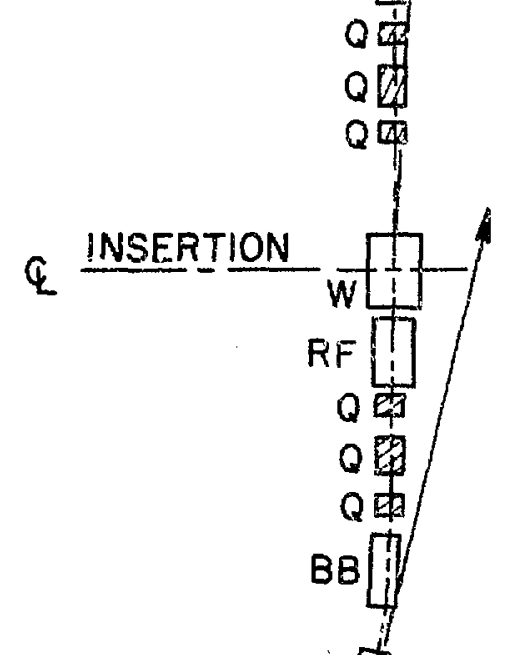

PROJECT NO. 78-CH-004

June 1970

BHL 21589

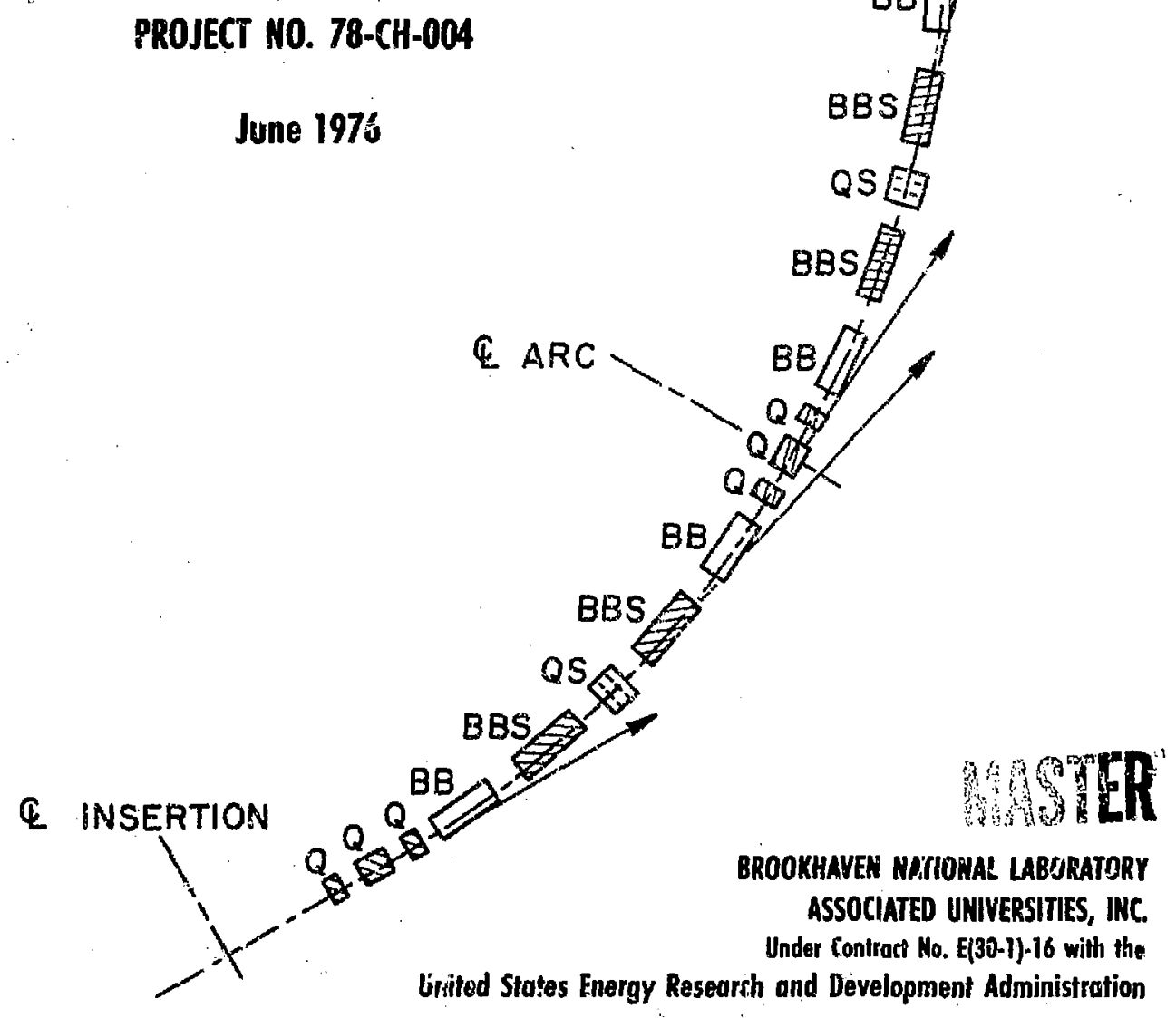


PROJECT NO. $78-\mathrm{CH}-004$

June 1976 



\section{PURPOSE}

The purpsse of this Rep̧ort 15 to deflne, In general outline, the extent and proportions, the type of construction, the schedule for accomplishmeat, and the estimeted cost for a new Synchrotron Radlation Fac1lity, as proposed to the Esergy Resesrch and Development Administration by the Brookhaven National Laboratory. The Report is concerzed only Indirectly with the selentific and technological justiflcaton for undertaklrg this project. The latter is ajdressed explicitly in separate documents (the Sshedale 44 and a porposal book). The Repart does consider user requirements, however, in order to establish a basis for design development. Preliminary drauings, outline spestfications, estimated cost data, and other descriptive natertal are included as supportIng docurantation on the current status of the project in this preconstruction phase. 
I. INTROOUCTION 1

II. Desion asis 4

A. The Synchrocron Rediacton Spectrum to

B. Opricel Churectertactes 9

C. User Requiremats and Aseoched Denisn Criteris 13

III. STORAQ AING SYSTEMS 18

A. Caneral Design Constderazione 18

B. The 2 GeV Ritg 34

C. The 700 MeV ating 36

D. The Injection syoces 37

IV. GULDMCS WW GILITIES 42

A. Foundarion tase 43

9. Struczure 44

C. Powne 45

D. Cooling 46

E. Surertial Hending 46

P. Sise 48

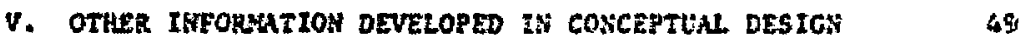
A. Shiteling
B. Hisblera
C. Experimental Equipment

vI. COST ESTINTES AND PROJECT SCHEDULS 62

A. Construction Schedule $\quad 62$

A. Happower 62

C. Cost Eethate 62

D. Resesereh end Developsene 65

E. Faclitiy Operation 66

VII. OTtER CONSIOERATIONS is

A. Codes, Standards, Qualizy Assurance 75

B. Mathods of Performance 79

C. Environdental Protection Requlrements 80

D. Health and Safery 80 


\section{INTRODUCTION}

Th1s project uill provido a satlonsl dedicated faciliey for muleddisciplinary research wish synchrocron radiecion, a poverful investigative 2001 of anfor isportance for the materials, solecular, and l1fe setences. The faciliey is propused not only because of tes value for fundabencal research in chese broad areas, but also because of 1 s leportance for experisental and dismoseic inveselgations directly relewane to practical energy and envizoneental concerna of the nation.

There are several cheracteriscles of che synchrocron light emitced frov an tectron scorage riag thich whe le unlquely useful co any classes of resesch. The spectrup is conclauous, utich radiaclon produced ac wueleagche elcher not avallable fron other sources or avalltble only at feeble incensity. The incensicles schlevable are exceptonally high, and since the eatsalon occurs fron very swall volune and is Aighly colifeaced, che source is excresely bright. Further, beaws are scable in posteion and inceasiey, and are highly polarized. Photoas are entered la nanosecond widch pulses wich separazions becween pulses of a teu cens of anaseconds up to bout a alcrosecond. Th1s the struccure can be explosted for the study of dymalcal properties and kinetic processes. Finally, electromenetic radiacion is eaicted from all curved regions of the eloctron orbit, and thus any photon users any be accamnodated simulcareourly.

Doch in this country and abrosd, hovever, sciencifle and technologtcal investgations using aynchrotron radiation have beea limited by the characteriselcs of presently avallable sources. The few exiscing facil1cles dedicated solely to this research are sall and provide spectra extending from long wavelengtho only to tha far uleraviolet. Those sources which can furnish photons at $x$-ray wavelengths vere designed for 
and have been used mainly for high energy physics, with serfous atcendant shortcomings for synchrotron radiation ut:lizatior. Moreover, many of these sources are synchrotrons and do not have the beam stablilties provided by a storage ring. Thus, it has been widely recognized that thare Is an urgent need for specially designed facilities Intended exclusively for research with synchrotron radiation.

The design approach for the proposed Brookhaven facility evclved irow an interdepartmental study initlated at the Laboratory in 1971, along with extersive and continuing contact with outside members of the potentfal user commity. It was concluded that user requirements could be wet most effectively by incorporating two storage rings in a single facility opezation. With this approach it was then posslbie to develop a conceptual design optimizing optical characteristics for $x$-ray users In one ring, and for users of vacuum ulcraviolet (VUV) radiation in the ocher. The rings are designed for flexible operation over electron energy ranges extending above $2 \mathrm{GeV}$ in the $x$-ray case, and up to $700 \mathrm{MVV}$ for ti:e VIV. Each ring is designed for operation with circulating currents apprsaching 1 aupert.

An overall layout of the facility is shown in Figure 1 . Electrons are injected from a $50 \mathrm{MeV}$ linear accelerator into a $700 \mathrm{MeV}$ booster symchrotron. Surrounding the Inac and booster is the $2 \mathrm{GeV} r$ ing; infection takes place in one of the long straight sections of the large ring. The small $700 \mathrm{MeV}$ storage ring, located nearby, is served by the same injection system. 


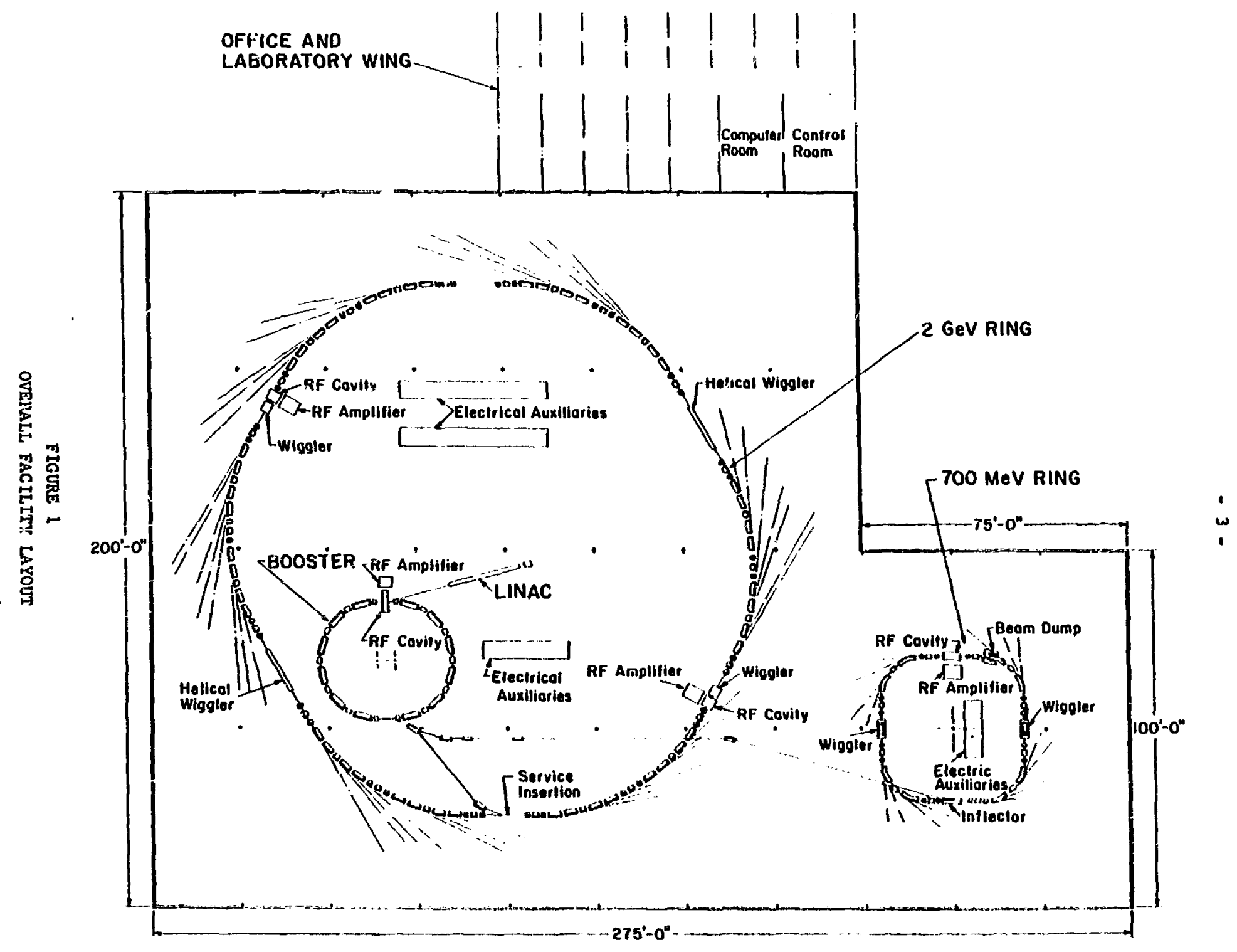




\section{DESIGN BASIS}

\section{A. The Synchrocron Radiacton Spectrum}

Relativistic electrons travelling in a curved path in a tagnetic field ente electromagnetic radiation covering a very broad spectrum. The radiaction patcern is strongly peaked in the fosward direction, coning off approxtrately tangentially to the curved electron orb1t. At any socent the radiation from an electron is contalied in a cone of ros halfwidth approxtacely $1 / \gamma$ radians, where $Y$ is the racto of aass to rese mass of the electron. The radiation is strongly polarized, the degree of polarization varying wth angle within the radiation con:. It is enteted from a very smal: source, of the order of ${ }^{3}$ in voluse.

Incensicy as anceton of wavelengeh and angular distribution of the synchrotron radiation is convententy expressed in teras of a characteristic wavelength,

$$
\lambda_{c}-4 \pi 0 / 3 r^{3}
$$

or

$$
-3.50 \mathrm{O} / \mathrm{E}^{3}-186 / \mathrm{BE}^{2}
$$

with the wavelengeh in $i$ units, the radius of orbit curvaturs 0 in $a$, the magnet1c fleid in kllogauss, and the electron energy in GeV.

At the large values of $\gamma$ appropriate for the GeV range of eleceron exergies of concem here,

$$
Y=1957 \mathrm{E} \text {. }
$$

Similarly, the energy is nearly proporticnal to momentum and the magnetic rigidicy can be approximated by

$$
B D=33.35 \mathrm{E} \text {. }
$$

A useful intensity vs. wavelength function is the number of photons emitted in all vertical angles per $\Delta \lambda$ for constant resolution 
$(k=\Delta \lambda / \lambda)$. If $\mathrm{N}_{k}(\lambda)$ is the number of pliotons emitted per (sec, ma of electrons, m-rad of circular aec, $k \lambda$ in $\dot{A}$ )

$$
\mathrm{N}_{k}(\lambda)=k \gamma F_{2}\left(\lambda_{c} / \lambda\right)
$$

where $F_{2}$ is a function only of $\lambda_{c} / \lambda$. Thus if a value of $\lambda_{c}$ is set by adfusting both $E$ and $B$, the flux per $k \lambda$ will be proportional to $\gamma$ (1.e. E).

The number of photons per m-rad of vertical angle, $\Psi$, at $\Psi=0$ and per sec, ma, m-rad of arc, $k \lambda$ is

$$
N_{k}(0, \lambda)=k r^{2} z_{1}\left(\lambda_{c} / \lambda\right) .
$$

For a set value of $\lambda_{c}$ the flux per unit vertical angle wlll then vary as $\gamma^{2}$.

The functions $F_{1}$ anc $E_{2}$ are shown plotted vs. $\lambda / \lambda_{c}$ in Figure 2 , together with spectral. distribution plots $\left(N_{k} / \lambda\right)$ vs. $\left.\lambda\right)$ for various combinations of E and $\mathrm{B}$. Norualized angular distributions of the linearly polarized componencs of radiation for varlous values of $\lambda / \lambda_{c}$ are shown In Figure 3. The abscissa is $\gamma \Psi$ and so for a set $\lambda / \lambda_{c}$ the angular distribution will shrink with Increasing $\gamma$. In Figure $3,100 \%$ is equal to $\mathbb{N}_{k}(0, \lambda)$. It is apparent that experiments making direct use of the polarization should be carried out near $\lambda_{c}$ for best conditions. 


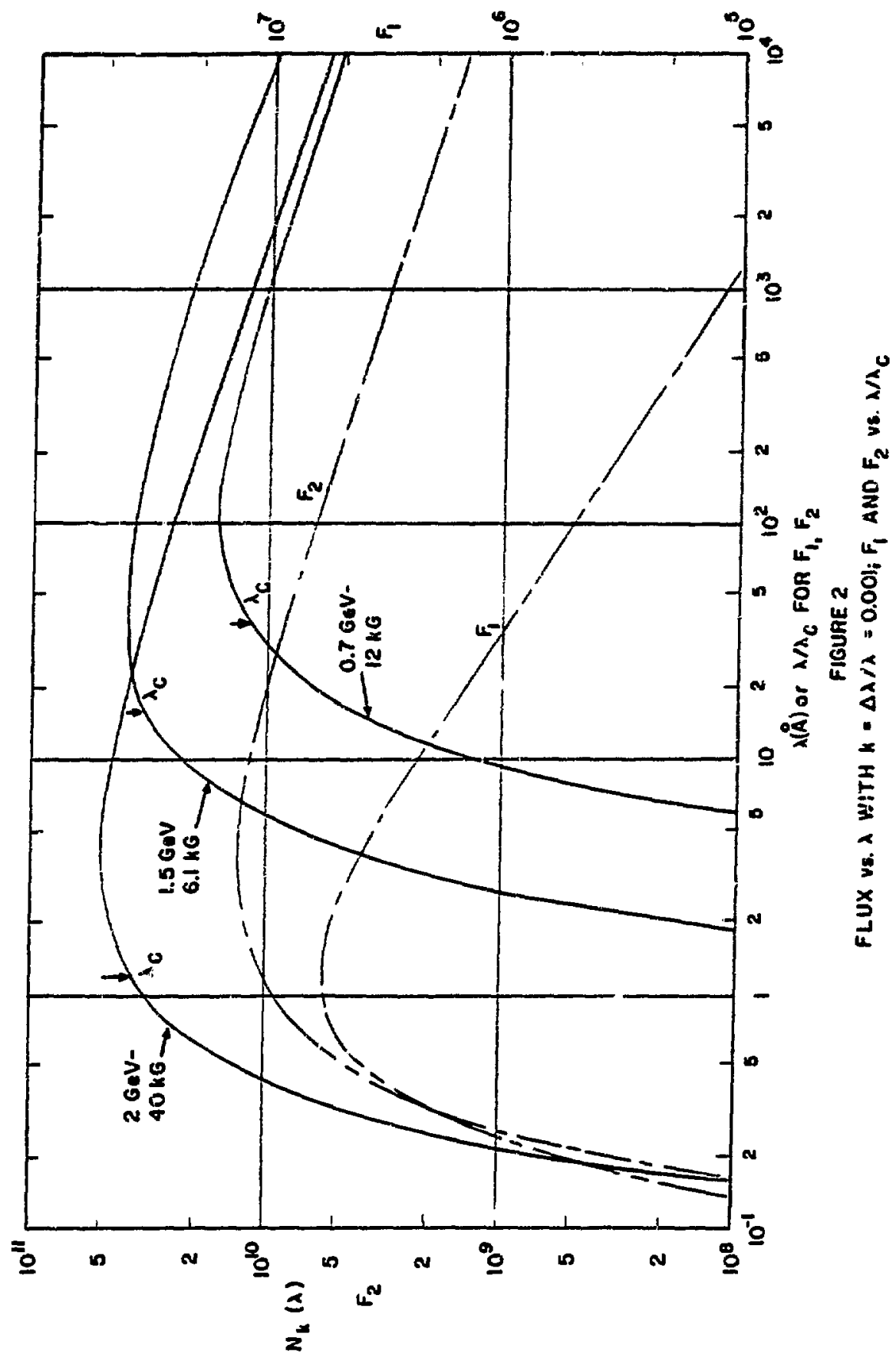




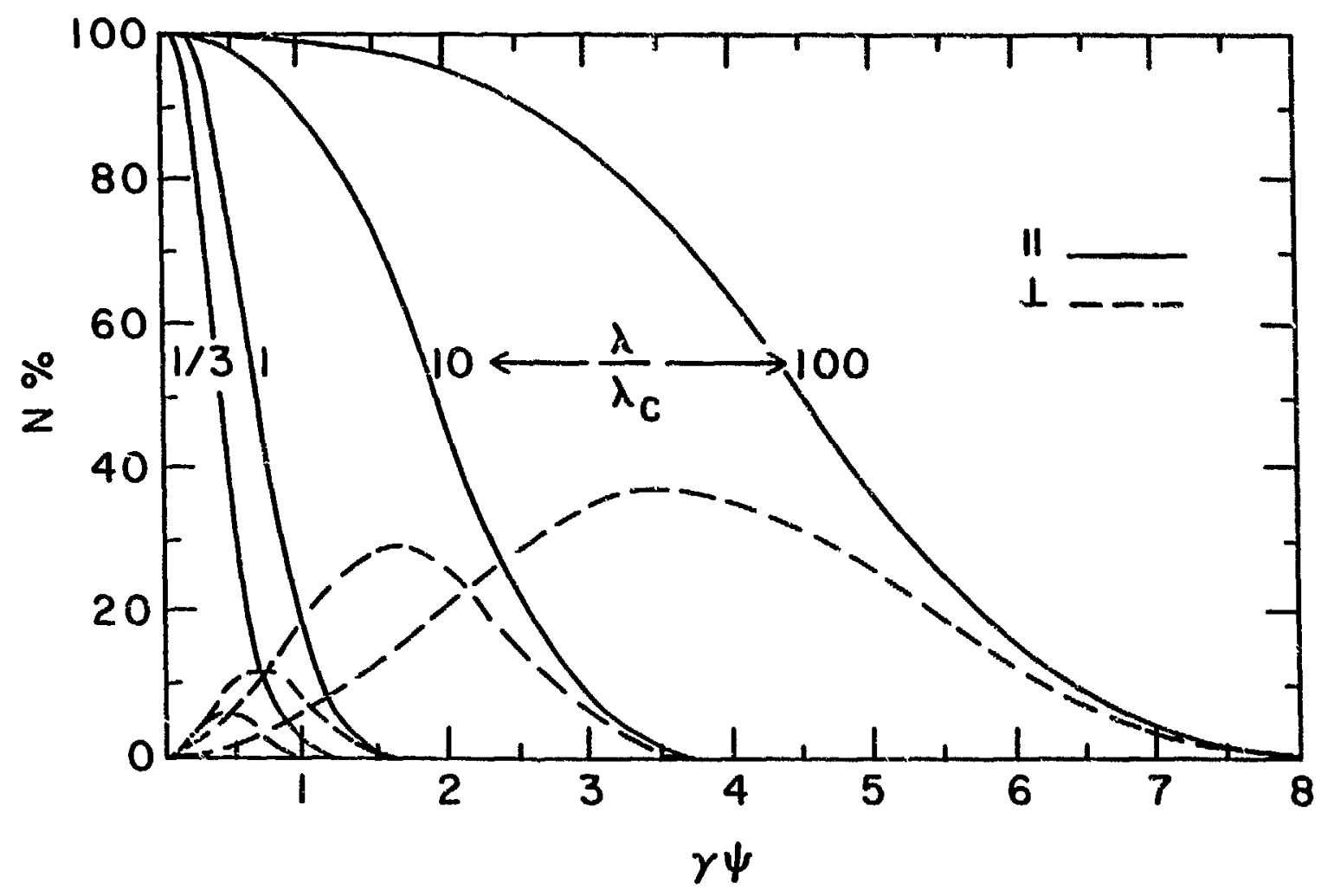

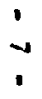

FICURE 3

ANGULAR DISTRIDUFIORS OF

I.INEARI.Y POIARIZED) CONIONENIS 
Since the flux in all vertical angles is proportional to E for a fixed value of $\lambda / \lambda_{c}$, and per unit vertical angle is proportional to $E^{2}$, it might seem at first sight that the design energy of a storage ring should be set at the highest feasible value. Rf power in the range of hundreds of kilowatts to megawatts must be considered, however, and it is not a trivial watter either to generate or to dissipate it. (The users will typically employ radiation from $10^{\circ}$ or so of the magnet.ic bend, leaving the radiation from the remaining $350^{\circ}$ to be absorbed by water cooling.) The total energy radiated by an electron per revolution around a ring is

$$
E_{T}(\operatorname{ReV})=88.5 \mathrm{E}^{4} / 0\left(\mathrm{GeV}^{4} / \mathrm{m}\right)
$$

For I amps circulating the total radiation power, which is also the rf power that must be supplied continuously, is

$$
88.5 \mathrm{IE}^{4} / \mathrm{o} \mathrm{kw} \text {. }
$$

Note that the radius of curvature of the orbit $\rho$ is proportional to $E / B$, so that the rf power is proportional to $E^{3} B$. Since $\lambda_{C}$ is inversely proportional to $E^{2} B$, it is more economical in power to decrease $\lambda_{c}$ by increasing $B$ rather than $E$.

From a user's point of view, the important questions relating to radiated power are how wuch represents a gain in useful photon flux for his experiments and how much is just creating problems in optical element design and location and in unnecessary background. The radiation beam sweeps out a thin sheet with emission in a vertical semi-angle of $\sim 1 / \gamma$ 
and the power density In this beam can be very large. An approximation of power per unit area, useful for estimating, is

$$
\mathrm{F} / \mathrm{A}=1.4 \mathrm{E}^{5} / \rho \mathrm{D}^{2} \mathrm{kw} / \mathrm{cm}^{2} \mathrm{amp}
$$

where $D$ is the distance in $m$ from the source. At several GeV, and moderate current levels, the flux can be so high that no optical element can survive very near the source. The percentage of radiation power at wavelengths greater than $\lambda$ is shown in Figure 4 as a function of $\lambda / \lambda_{c}{ }^{*}$ Users working in the UV clearly need a long $\lambda_{c}$ spectrum in order to avold the powerful $x$-ray contamination accompanying a short $\lambda_{c}$.

\section{B. Optical Characteristics}

A synchrotron light source is a specialized single-beam electron storage ring. Alternating-gradient focuss ing coupled with avallable technology permits wide latitude in the design of a storage ring, but one must make choices which balance performance against cost and complexity. Since this source is proposed for diversffied research in spectroscopy, the characteristics of the electron beam are important primarily as they affect the properties of the emitted radiation. This introduces quite different considerations from those involved in a design for high energy physics. One is not only concerned with obtaining high photon fluxes over appropriate spectral distributions, but the quality of the electron beam as a bright optical source also becsmes very Importarit. In addition, the design geometry must be adapted to emerging 1ight pipes and to the optical element and spectrometer configurations desired by isers.

A designer is not limitec to arc bending magnets for providing optical sources. Use can also be made of moderately long insertions, sometimes called long straight sections or Collins straight sections, by 


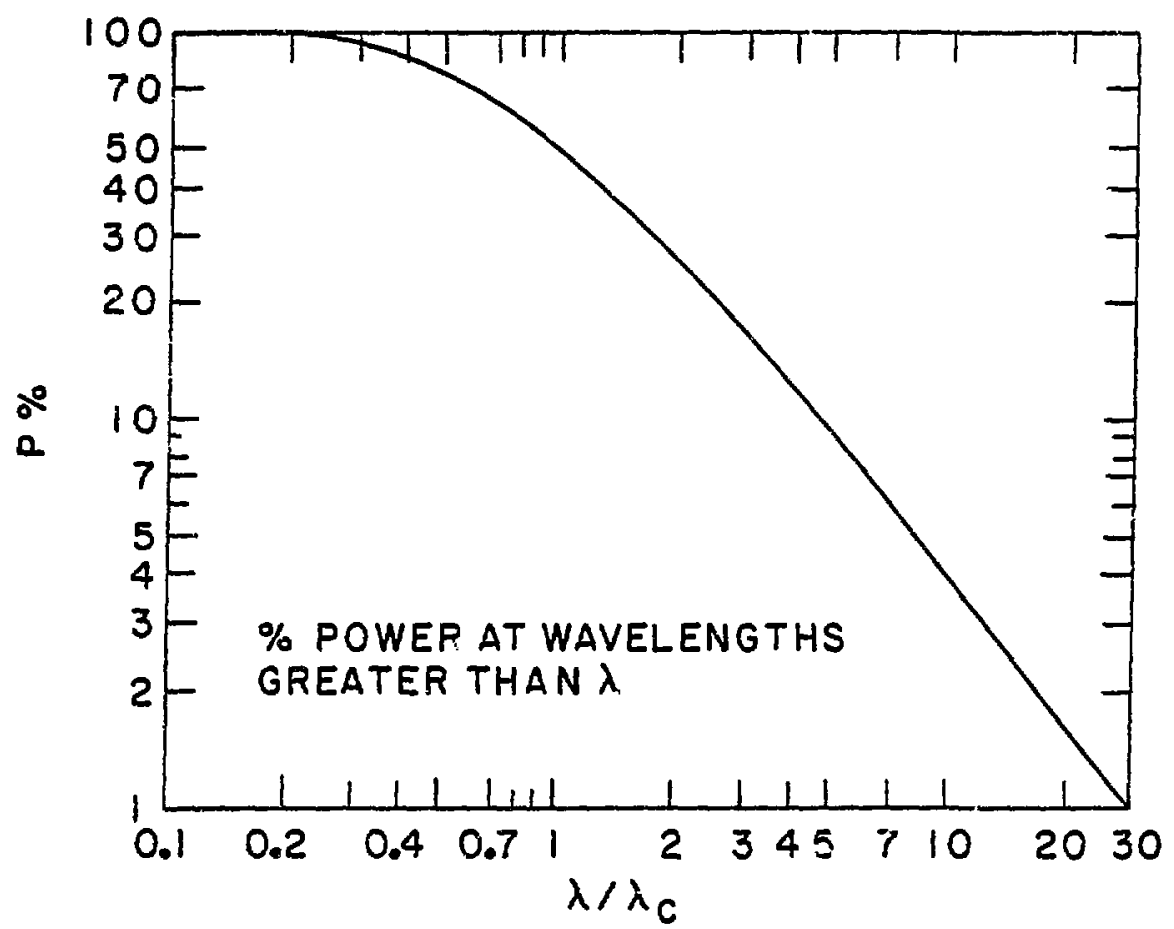

FIGURE 4 
Introducing wiggler magnets at their centers. Each wiggler consists of a multiple dipole which will produce alternating bends, "wiggles", In the electron beam, but no net deflectlon. The insertion must be matched to the arcs with magnetic lenses which can be designed to focus in both horizontal and vertical directions at the insertion center. Design of the entire ring lattice must produce particle orbits which are not markedly disturbed by the presence (or absence) of wigglers in the insercions. When properly designed such insertions can provide sources with very favorable optical propertles for spectroscopy and diffraction.

Optical charccteristics of electron storage rings have been examined in detall at Brookhaven in the course of conceptual design. Varlous types of wigglers were considered in this study, high and low field dipole multiplets, as well as the recently proposed wigglers with helically varying flelds. The optical source quality obtainable from the arc bending magnets has also been studied. Calculations showed that a storage ring could be specially designed to provide extremely bright optical sources.

The electron beam has a distribution in transverse dimensions and angles given at any point in a specific ring lattice design by certain functions defined and discussed later in III.A. A real source subtends an arc and is extended in the direction of the optical axis as well as In the transverse dimenstons. The source can be diagrammed in phase space by transforming radiation from each element along the are to the arc center. The resultant phase space area then depends on several quantitles: the transverse divergencies and sizes of the electron beam, the length of the source, and the opening angle of the cone around the electron orbit within whisn the radiation is emitted. Taking into account 
these various factors, one establishes the following requirements for optimizing the optical features of the storage ring light sources:

1. Very small electron beam enittances (see III.A.1).

2. Low B points (see III.A.1).

3. Smallest possible bending radius, compatible with wavelength demands and power limitations.

In the present $2 \mathrm{GeV}$ ring design, electron emittances have been minimized by the choice of a particular storage ring lattice which differs substantially from those used in electron rings built for high energy physics, and this design leads to an improvement by a factor of $\sim 10$. Low $B$ points are obtained by introduction of matched insertions. High fleld wigglers in those low $B$ points further increase the source brightness in these locations because of the small bending radii associated with the high magnetic fields. A separate small radius $700-\mathrm{MeV}$ ring provides VV sources optically superior to those avaflable In the arcs of the 2-GeV ring.

In sumbary, a prime obfective in the Brookhaven design effort has been to provide vexy bright optical sources over the full spectral range - hard $x$-ray through the UV. A single ring designed to meet optimally the needs of $x$-ray users could also provide a few UV sources, at the expense of high brightness $x$-ray sources, by using low field wigglers in some straight sections. The optical needs of UV users, however, can be met in more nearly optimum fashion by the numerous sources which can be provided in a separate lower energy ring spectally designed to serve their experiments. 


\section{User Requirements and Associated Design Criteria}

\section{Spectral Distributions}

The avallability of photon spectra peaked in different wavelength regions is a basic requirement for the community of syachrotron radiation users. The major reason for this is that soft radiation users need to have photon beams uncontaminated by the troublesome radiation at hard $x$-ray wavelengths, as discussed already in the last paragraph of II.A. There are also significant advantages to be gafied by providing several spectral distributions, at spaced values of $\lambda_{c}$, so that various classes of experiments can be undertaken simultaneously under near optimum conditions.

Experiments in the hard $x$-ray region require spectral peaking in the vicinity of $1 \dot{A}$ with radiation at useful intensity levels extending down to some tenths of Angstrom units. Th1s requirement will be wet by the large ring in the Brookhaven design, when operated at $2 \mathrm{GeV}$ with $40 \mathrm{kG}$ wigglers. A clear need for spectra peaked below $1 \mathrm{~A}$ has so far not been documented, but substantlally shorter wavelengths could be achieved by using higher field wigglers and by some increase in ring energy. The $40 \mathrm{kG}$ wigglers in the design are easily within the stateof-the-art, but 1t should be possible to develop $60 \mathrm{kG}$ or even higher field wigglers if warranted by future user needs. The design margin in the facllity (apecifically in the rf syotew, quadrupoles, and bending magnets) w111 permit operation of the large ring at energies as high as about $2.4 \mathrm{GeV}$ if need be.

Spectra sultable for the soft radiation users will be provided by the small ring in the srookhaven design. When operated at its maximum energy of $0.7 \mathrm{GeV}$, for example, the small ring will provide a $\lambda_{c}$ of $32 \dot{A}$ from 1 te arc magnet ports and $19 \dot{A}$ from a $20 \mathrm{kG}$ 1ron-copper 
wiggler In addition, a spectrum with $\lambda_{c}$ at $5.7 \dot{A}$ will be avallable from the arc wagnets of the large ring (when operated at $2 \mathrm{GeV}$ ).

\section{Brightness}

For experiments requiring high spatial resolution there is no substitute for high source brightness (photons/sec- $\dot{A}_{-m}^{2}$-steradian). While not necessary for some types of experiments, it is never a disadvantage. A basic alm at Brookhaven has been to provide photon sources of the highest practical irightness, and the design will yleld brightness greater by at least an order of magnitude than that of any existing synchrotron or storage ring.

\section{High Current Capability}

Since photon flux is directly proportional to the clrculating current in a storage ring, it is obvlously advantageous to provide high current capability in a storage ring designed spectfically for synchrotron radiation research. There are practical considerations, however, which limit maximum design currents. Among these is an adverse effect on the lifetime of the stored electron beam. Also, at some point there can be real problems in dissipating the high potver densities of the synchrotron radiation itself as it impinges on optical elements and vacuum walls, as evident from the discussion in II.A. The Brookhaven rings are designed for operation with circulating currents approaching 1 ampere. This objestive leads to an injection energy of about $700 \mathrm{MeV}$. While the ring booster designed for this purpose is a relatively simple device, it is somewhat more sophisticated than originally envisioned. In particular, the experiments planned with helical wigglers in the storage rings impose requirements not considered in the earlier prelimluary design plans. 


\section{TIme Structure}

The time structure of the bean is expected to be very Important for a varlety of experiments. A storage ring can be loaded with as many electron bunches as the rotation time divided by the rf perfod, or as few as one. Important factors in radio frequency selection are cost, avallability, and tube replacement costs of the rf generators. A pulse width of about I nanosecond can be obtained easily and should be adequate for much of the work under current discussion in the user community. Narrower widths are achlevable, however, if user demands warrant the additional cost. This is left as a possible improvement for the future.

\section{Operational Flextbility}

A point emphasized in both Internal discussions and consultations with members of the outside community has been that a new dedicated facility design should peralt a range of operating conditions, so as to meet special experimental requirements as they might arise, and that reasonable allowances be made to cover posslble future demands for expanded capability. The storage rings in the Brookhaven facility will have good performance characterlstics over a range of energles and c1rculating currents. ' . various spectral distributions will therefore be tunable with energ: and fleld to meet special experimental needs. An Important advantage to be gained from such tunabllity, for example, is that the working wavelength for an experiment can be set on the rapidly falling slope of the flux curve for strong suppression of higher order contamination of a monochromatized photon beam. In addition, for experiments where polartration may be of critical Importance, it will be advantageous to adjust $\lambda_{c}$ to be near the working wavelength (see Figare 3 ). 
Considerable advantage is gained in operational flexibility by providing two rings tn the facllity. Changes in operating conditions which may be desired by soft radiacton users, for example, such as tuning $\lambda_{c}$ by variations in $E$ and $B$, can be made without disturbing conditions desired by hard radiation users.

There is much current discussion on the feasibility of hellcal wigglers. Should suck a device prove to be practical in a storage ring, it can be accomodated in the framework of the Brookhaven design. Spectal attention has been given to helical wigglers 1 in the course of conceptual design; the fields and orbits in hellcal wigglers have been ar.alyzed and stabilicy cricerta have been applied to the orbits in a storage ring that includes such devises. The conclusion is that their use should be enti=ely possible. Extra length, therefore is being allowed in some straight sections and the injection booster has been re-designed to provide necessary dampling characteristics.

Allowances for posstble future needs for $x$ rays belos $1 A$ have already been mentloned in connection with the development of higher field wigglers. Continuing work in the latter area should be emphasized in the post-construction operational phase of the profect even if no significant demand for shorter wavelengths emerges. Significant savings In rf power consumption could ie reallzed by operating the large ring at lower energies.

\section{Bead Lines}

In first approximation the scope of a storage ring profect followe in atural way from the comblnations of electron energy and magnetic field required to produce the radiation to be used in experiments, In decail, it is decexmined by the maximum number of developable beam lines and their Individual requirements in optical characteristics. 
The deslgn group can then settle on a definlte ring symetry (which will determine the mean ring circumference), and an assessment car be made of the buflding space required for experimental and facflity operations. It is abundantly clear that the scientists who would make fmediate use of a new dedicated facility, spectally designed and operated to meet their needs, already number in the hundreds. The number of probable user: Jf synchrotron radiation in the nation over the next decade can only be approximated, but it is certatnly very large. The decision was made to provide for ultimate development of about 35 ports at the large ring, and about 16 at the small ring. Since a beam port can serve more than one experimental station (In most cases), the facility will be a sizeable operation when it reaches saturation. With this capacity, Brookhaven will be able to meet a major fraction of projected needs in the external community, in addition to serving the requirements of its internal ERDA programs.

There are fimportant beam line apparatus components which must be thought of as integral parts of a synchrotron radiation facillty. Their design in many cases must be meshed interactively with detalled design of the storage rings if the Installation as a whole is to realize its full potential. Among such components are optical elements, certain complex photon detectors, some ultra high vacuum 1tems, special spectrometers, and computer systems. Development will be needed for some of this equiptent. 
III. STORAGE RING SYSTEMS

\section{A. Geseral Design Considerations}

As discussed in II.A., the wavelength of the peak of the radiation spectrum is inversely proportional to $E^{2} B$, whereas the if power, for a given circulating current, is proportional to $E^{3} B$. Thus the wavelength of the spectrum peak can be shortened at less expense in $\mathrm{r} f$ power by increasing $B$ rather than by raising $E$. Also only a small portion of the radiation from the electrons distributed around the necessary $2 \pi$ of bend can be brought out for use. These considerations lead to the concept of short sectors of high magnetic field interspersed among sectors of relatively low fleld.

\section{Particle Dynamics}

The lattice of a synchrotron or storage ring is composed of a sequence of bending and focusing magnets. The functions of bending and focusing can be tncluded in the same magnet or separate magnets can be used for bending and focusing. The latter "separated function" system 1s the one that is proposed for the rings in the Broskhaven facility. The radial and vertical motion chrough such a lattice is described in the classic paper of Courant and Snyder (Annals of Pinysics, 3, 1, 1958). An Important function discussed by Courant and Snyder is the araplitude function B. If $x$ is the radial displacement from the "equilibrium orbit", $y$ 1s the vertical displacement and s represents distance along the orbit then

$$
\begin{aligned}
& x(s)=A_{x} \beta_{x}^{1 / 2}(s) \sin \left(\int \frac{d s}{\delta_{x}}+\phi_{x}\right) \\
& y(s)=A_{y} \beta_{y}^{1 / 2}(s) \sin \left(\int \frac{d s}{s_{y}}+\phi_{y}\right)
\end{aligned}
$$

where $A_{x}, A_{y}, \phi_{x}$ and $\phi_{y}$ are deternined by intefal conditious. 
The amplitude function $B$ has the perlodicity of the magnet lattice; Its value can be determined by methods described by Courant and Snyder. Numerous computer programs are avallable for its numerical determination. When the distribution of the amplitudes and angles of the paths of all of the electrons in a jeam are plotted in $x, x^{\prime}$ or $y, y^{\prime}$ phase space, the area of the distribution (elliptical in shape) is referred to as the "emittance" of the beam.

As can easily be seen from the expression for $x(s)$ and $y(s)$, the beam size w1II vary as $\beta_{x}^{1 / 2}$ and $G_{y}^{1 / 2}$ around the machine. Low $B$ points are provided at a number of places in both the $700-\mathrm{MeV}$ and $2-\mathrm{GeV}$ rings to give maximum beam brightness.

One wavelength of the "betatron" oscillation is completed when

$$
\int_{s_{1}^{5}}^{s_{2}} \frac{d s}{s}=2 \pi
$$

Integration around the complete clrcumference will now yield the V-value, the total number of betatron oscillation periods in one revolution. To avold destructive resonance effects the wachine should be designed to have a v-value that is not close to an integer plus a small rational fraction.

An off-momentum particle will travel an a different equiIfbrtum orb1t, which, in general, is not parallel to the central orbit but will be one with wiggles correlated with the magnet lattice. The monentum dispersion function $X_{p}(s)$ is defined as

$$
\Delta x(a)=Z_{8}(a) \frac{\Delta p}{P_{0}}
$$


where $\Delta x(s)$ is the local setover of the equilibrlum orbit for a momentum deviation $\Delta p$ from the central orbit corresponding to the momentum $\mathrm{P}_{\mathrm{o}}$. Like the B-function, $x_{p}(s)$ has the perfodicity of the magnet lattice. As can easily be seen from the discussion of radiation power In II.A., the voltage per turn in $\mathrm{kV}$ necessary to make up for the radiation loss is given by

$$
V_{T}=88.5 E^{4} / \rho(E \text { in } G e V, \rho \text { in } m) .
$$

During the acceleration cycle, as the electron beam energy is increased from the Injection to the operating level, an additional voltage $\mathrm{V}_{\mathrm{a}}(\mathrm{keV} / \mathrm{turn})$ is required:

$$
v_{a}=\cos _{0} \times 10^{-4}\left(C \text { and } \rho \text { in } \mathrm{m}, \dot{\mathrm{B}}_{\mathrm{o}} \text { in kgauss } / \mathrm{sec}\right) \text {. }
$$

Here $C$ is the ring circumference, $\dot{B}_{0}$ the magnetlc gulde fleld rise rate. The rf system supplying the voltage must operate at a frequency which is an integer ( $h$, the harmonic number) times the revolution frequency of the electrons. Under these conditions, particles with momentum and phase (relative to the rf voltage) within a range around the stable phase angle (see below) and the central momentum, w11l undergo stable phase or synchrotron oscillations. The stable regions in long1tudinal phase space are called if "buckets". There will be h equally spaced buckets and the electron beam can occupy any number or them, depending on the filling mode. In other words, the electron beam will be In the form of 1 to $h$ bunches. In order for the electron bunches to fit Inside the $\mathrm{r}$ buckets it is necessary that the applied gap voltage $v$ be greater than $v_{r}$ in the storage mode and greater than $v_{r}+v_{a}$ in accelerating mode. The stable angle $\Psi_{0}$ is given by

$$
\sin \Psi_{0}=\frac{V_{I}}{V} \text { or } \sin \psi_{0}=\frac{V_{c}+V_{a}}{V}
$$




\section{Radiatioin and Damplng}

The emitted radiation affects the longltudinal as well as the transverse motion. An electron whose energy deviates from the nominal one will during one revolution emit a slightly different amount of energy. The reason is not only the different particle energy, but also the fact that an off-momentum particle travels on a somewhat different. the bending magnets where the radiation is emitted. This in turn leads to damping of the energy (or phase) oscillation amplitudes. The radiation effects on the transverse oscillations are different in the vertical and horizontal planes. During the rf acceleration that takes place every revolution to make up for the radiation loss, there is a reduction in the otherwise Invarfant vertical oscillation constant $A_{y}$, Introduced earlier, equivalent to damping of the vertical oscillation amplitude. The same is true for the motion in the radial plane, but here there is an additlonal effect causing antidamping rather than damping. When the electron emits radiation in the bending magnets, It moves to a different equilibrium orbit and there will be a change in the horizontal oscillation amplitude which is measured with respect to the instantaneous equilibrium orbit. This, together with the fact that the amount of radlated energy 1tself depends on the radial betatron amplitude, accounts for the antidamping. Fortunately, in a separate function machine with parallel edge bending magnets, the antidamping effect is zero and the entire radial damping effect obtalned from the Interaction of the electrons with the longltudinal ri accelerating field remains.

The effect of radiation on the synchrotion and radial betatron osclllations would be pure damping and hence negligibly small beam sizes if the energy loss would be a continuous process. Because the 
radiation is emitted in discsete quanta, the damping effects in the Iongitudinal and radial phase planes are counceracted by excftation of random walk type oscillations resulting in finite longitudinal and horizontal beam sizes. Radiation excltation of vertical oscillations comes from the finite but very small forward angle with which the radiation is emitted, and can in general be neglected. Observed vertical emittance is the result of linear coupling to the horizontal motion; this coupling always exlsts in the ring because of imperfections.

The radial emittance is highly affected by the size of the momentum dispersion function in the bending magnets, with low $x_{p}$ values leading to small emittancas. In the present storage ring designs this fact has been utilized in a double sense:

(a) The regular bending magnets are incorporated in achromatic arcs in which the $x_{p}$ function stays relatively small. Disregarding the wlgglers, such a design results in a radial emittance about an order of magnitude smaller than that found in more conventional electron rings of comparable energy.

(b) The high field magnets (wigglers) are placed in the center of Insertions in which the $X_{p}$ function is matched to zero outside the wigglers and reaches a maximum as low as $0.005 \mathrm{~m}$ inside the wigglers. This prevents any slgnificant Increase in the radlal emittance when the wigglers are curned on. In fact, In the present design, there is a slight decrease in the radial emittance coming from increased radial damping when the wigglers are on.

\section{Space Charge and Instabilities}

With a current of a significant fraction of an ampere, Intensity-related effects are to be expected. The space charge defocussing effect coming from the electromagnetic field, produced directly or 
Indirectly by the beam, is negligible for highly relativistic particles such as 1 - $2 \mathrm{GeV}$ electrons. A space charge effect that will reduce the Iifetime of the beam is the so-called Touschek effect whereby transverse momentum is transferred into longitudinal momentum by Coulomb scattering between particles. The bunches will grow in longitudinal phase space and eventually spill outside the rf buckets. The Touschek lifetime is inversely proportional to the charge density of each bunch and consequently will be particularly short in the present design where the transverse beaw dimensions are purposely minimized to achieve high beam brightness.

Transverse and longitudinal instabilities will be excited whenever there is a prop : phase difference between the coherent oscillations of the beam bunches and the electromagnetic forces induced by such oscillations in the environment of the beam such as the vacuun chamber and the rf cavities. In electron rings a single bunch transverse Instability of the headtail type is usually the most bothersome. Particles at the head of the tight bunches exert transverse forces on the particles at their tails through the wake fields due to finite resistivity of the vacuum chamber. However, as long as the chromaticity, defined as $\mathrm{dv} / \mathrm{dp} / \mathrm{p}$ is positive and greater than a given value, all important oscillation modes will be stable. Hence it is necessary to Install sufficiently strong sextupoles not oniy to cancel the existing natural negative chromaticity orfginating in the momentum dependent quadrupole focus-sing strength, but also to produce the necessary positive value of this parameter.

Other Instabilities to be expected are caused by higher mode excitation in the rf cavities and various parts of the vacuum chamber which lead to heat losscs as well. These can be suppressed by 
installing damping loops in the rf cavitles and by placing resistive absorbers in proper positions in the vacuum pipe, which itself will be designed to minimize rf excitation. Miltibunch modes, in which the bunches "talk to each other" can also be elfminated by decoupling the bunch motion transversely by use of an rf quadrupole and longitudinally by installing a second $r f$ system operating on a different harmonic number. Fecdback can also be used to damp varlous instabilities. A low harmonic number is desirable to minimize most of these effects and an rf frequency of $53.5 \mathrm{MHz}(h=24)$ was chosen as a compromise to avold excessively large rf cavities.

The high intensity effects described above have dictated the injection energy of $700 \mathrm{MeV}$ in both storage rings. Extrapolation of experience gained at CEA and Doris with operation in a many bunch mode Indicates thit accumulation of a beam current of $\sim 1 \mathrm{~A}$ is feasible at this energy.

\section{B. The $2 \mathrm{GeV}$ Ring}

\section{Lattice and Magnets}

The lattice of the $2 \mathrm{GeV}$ xing consists of six arcs matched to six insertions. The layout of one of the six identical sectors is shown in Figure 5, and its $\beta$ and $x_{p}$ functions are plotted in Figure 6 . Each arc is made up of two achromatic bends separated by a quadrupole triplet. The horizontal dispersion function $x_{p}(s)$ stays below $0.5 \mathrm{~m}$ in this design, and the radial emittance is about an order of magnitude smaller than that found in more conventional electron rings of comparable energy and designed for colliding beam experiments. The beam is brought to a low- $\beta$ focus $\left(\beta_{x}=0.57, \beta_{y}=0.35 \mathrm{~m}\right)$ in the cencer of each insertion by triplets adjacent to the arcs. The insertion center is also the 
location of the high-magnetic-fleld wiggler. It comprises three superconducting dipoles operating at fields cor-esponding to bends up to $3.7^{\circ},-7.4^{\circ}$ and $3.7^{\circ}$. The fields will be in the neighborhood of 40 kilogauss. Such a dipole triplet restores the beam to the equilibriuI orbit and has only a small effect on the radial emittance. It can be operated at flelds bearing any desired ratio to the flelds in the arcs (or even turned off). Although it is tempting to consider single highfleld magnets, the fields in such single dipoles must be tracked with the flelds in the other dipoles; the disadvantages outwelgh the saving in $\mathrm{rf}$ power. (Less than half of the radiation from the wiggler triplet can he brought out of the ring and so much of the power is "wasted".) Two sets of sextupoles (12 and 24 respectively) (SF and SD in Figure 5) are required to compensate for the relatively large horizontal and vertical chromaticity. Sextupoles SF will be combined with the quadrupoles QF in the center of each achromatic bend while sextupole!S SD will be incorporated in the adjacent dipoles in each half of these bends.

The bending magnets will be C-shaped and conventlonal in design. A cross sectir of a typical bending magnet is shown in Figure 7. The same magnet cross section will be used in the $2 \mathrm{GeV}$ ring, in the 700 MeV ring and in the booster; thus magnet laminations produced by the same die can be used in the magnets of all rings.

The lattice described requires some of the radiation beams to penetrate the outer edge of the quadrupole structures; a slot w1ll then be required, making the quadrupole structure analogous to a C-shaped dipole. Although some development work will be necessary, such magnets should be no real problem--judging from experience with narrow quadrupoles for beam transport which have been built at Brookhaven for several years. 


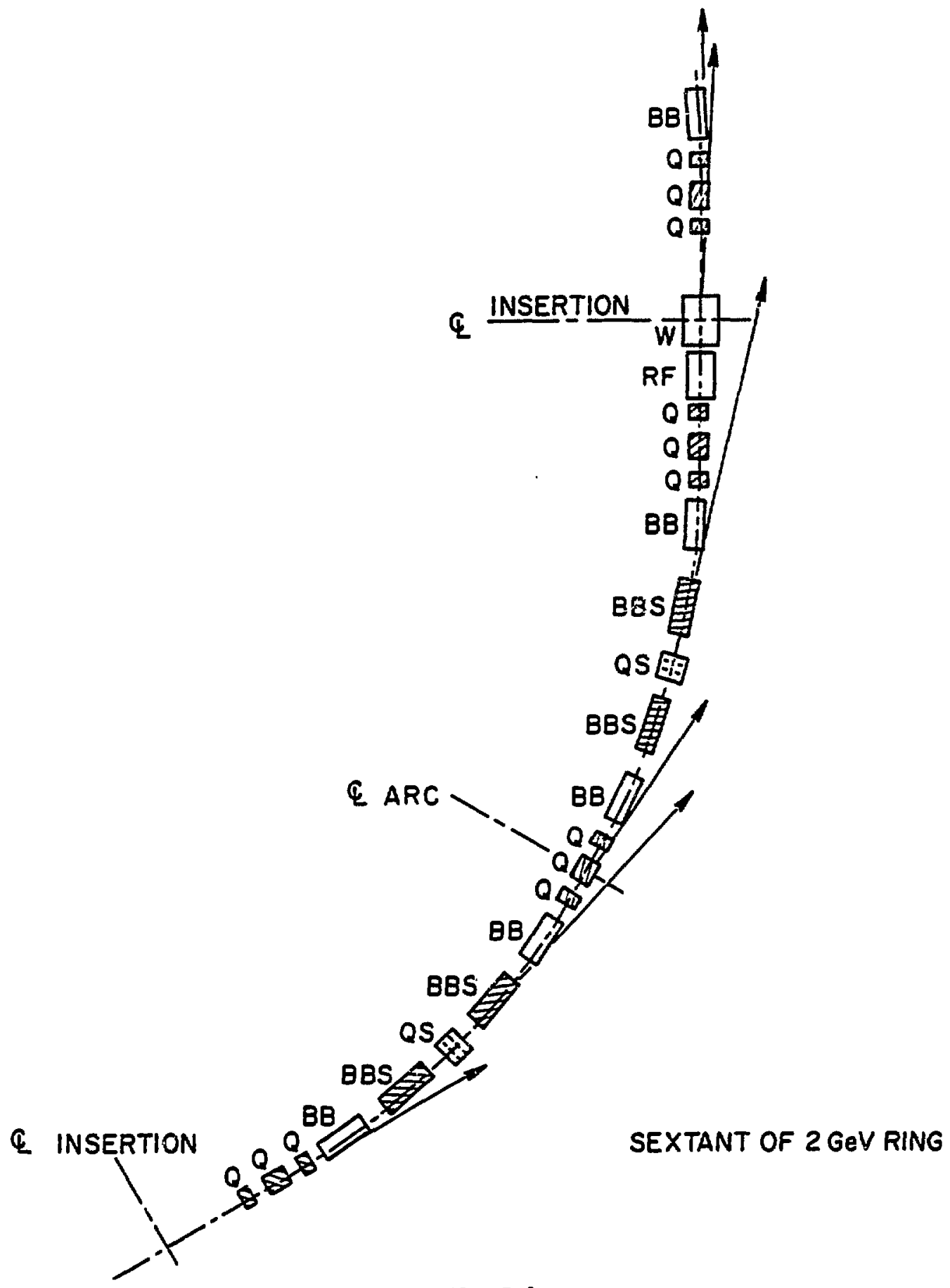




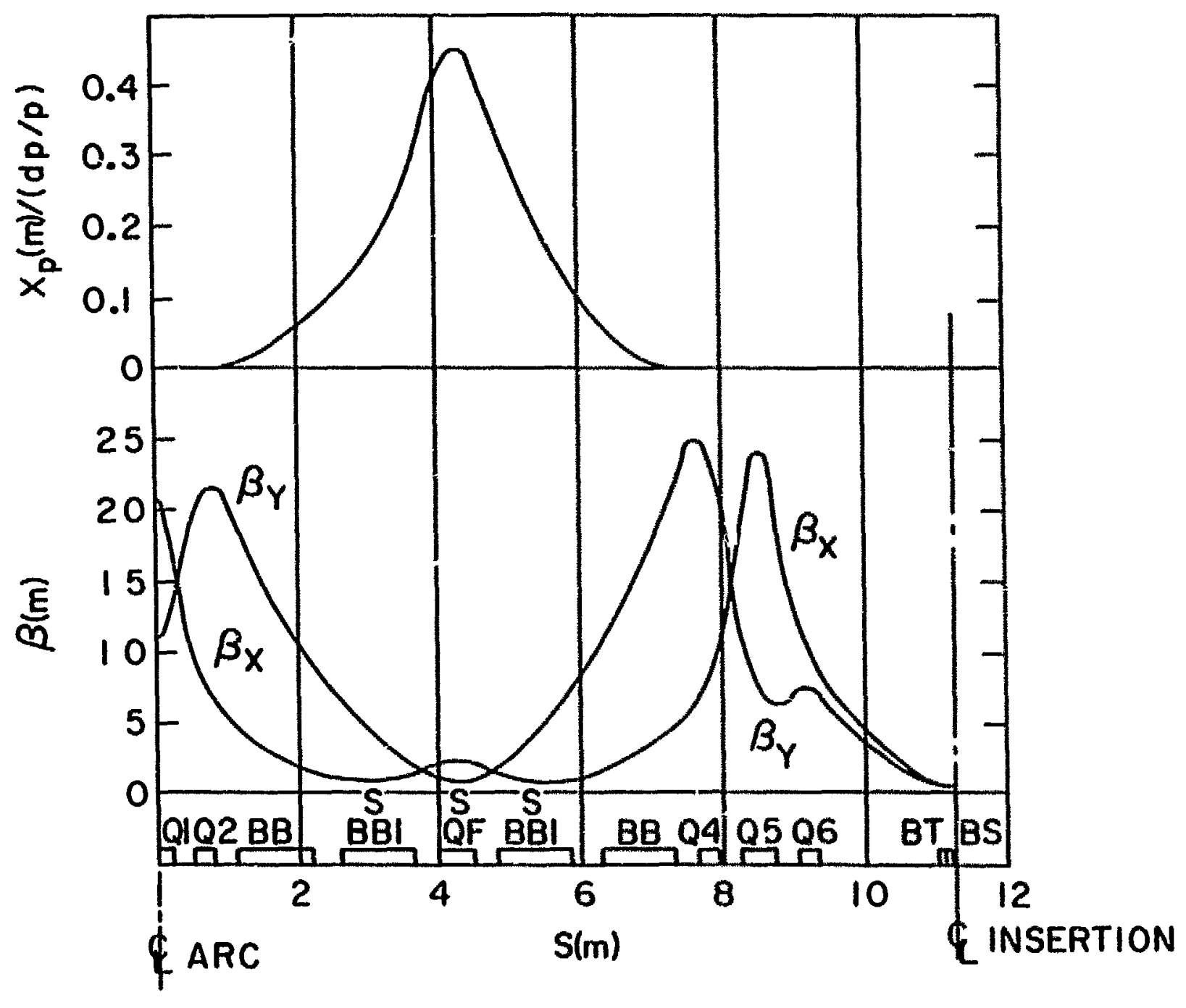




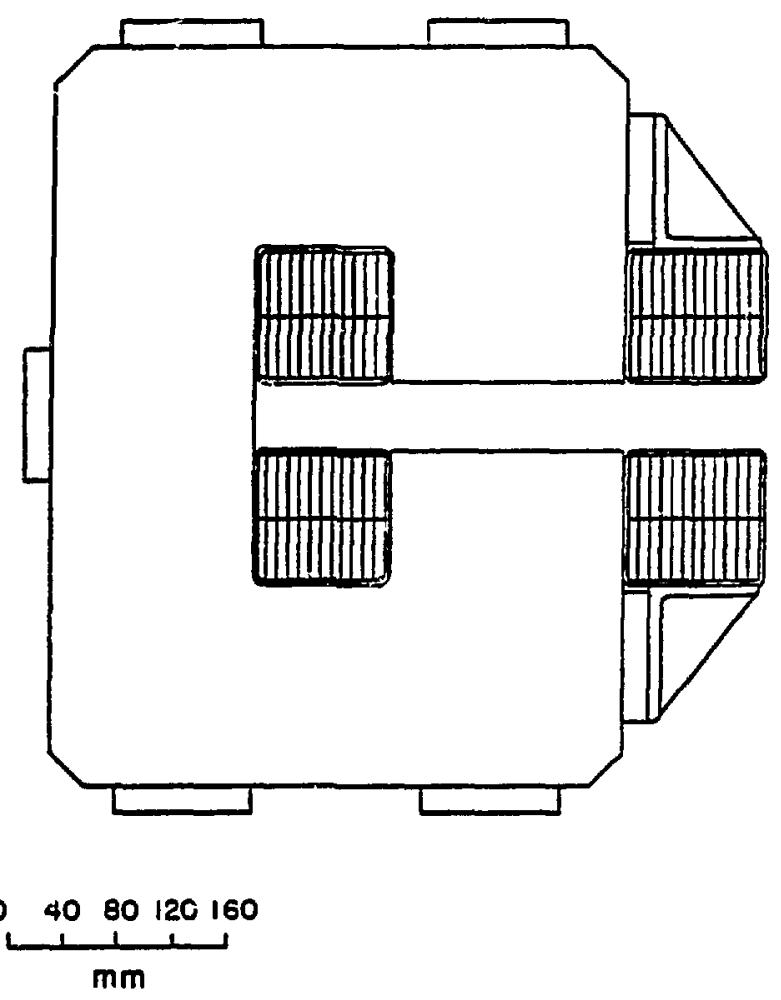

BENDING MAGNET

FIGURE 7 
Although the side sections of the Iron yokes of these quadrupoles are omitted, they st11l provide good field patterns. The side coll can be split and the two magnet halves separated to create a slotted quadrupole; the fleld shape can be corrected by contouring the Iron and by adding correction colls. Q1, Q2, Q4, Q5, and $Q 6$ would take th1s form and would require pole tip fields no higher than 10 kilogauss. QF will be a 12slot lens entirely surrounding the orbit. The SD sextupoles will be combined with the dipoles by contourting the fron and adding adjustable pole face windings.

The ring has the potential for ultimate development of 35 beam ports: 30 "simple" ports from the arcs and 5 speclally designed wide angle ports from the transverse wigglers in the stralght sections (one of the six stralght sections is reserved for machine servir.e functions). At $2 \mathrm{GeV}$ the radlation spectra will have $\lambda_{c}$ values of $5.7 \AA$ for the arc ports and $1.2 \dot{A}$ for the wiggler ports (at a wiggler field of $40 \mathrm{kG}$ ). Most of the arc ports will be capable of serving more than one experimental station, with the degree of multiple use depending upon the angle requirements of the various classes of experiments. Each wiggler port will be a broad multiple port, so as to avold the additional cooling requirements which would have to be met if more than one pipe were to be mounted close to the high power denstty wiggler sources. Agaln, depending on the class of experiment, each of these spectal ports could serve between 2 and 5 experimental stations. Thus, the ring will have a long range capacity for supporting quite a large research program.

Future use of helfcal wigglers is not excluded in the present design. Such wigglers would require free stralght sections of the order of $5 \mathrm{~m}$ in length. A small dipole and an additional quadrupole would be required at each end of these straight sections to preserve the 
equilibriut orbi: of the wachine and to accomplish matching of the hellcal wigglers to the ring. Alternate use of the longer straight sections for helical and ordinary wigglers is possible. However, if the low-B values of the shorter stralght sectiuns are to be reproduced, auditional double focussing doublets or triplets will have to be introduced into the longer Insertions.

\section{RF System}

The energy loss per turn of electron as it passes through the $8 \mathrm{kG}$ bending magnets is $175 \mathrm{keV}$. In each $40 \mathrm{kC}$ wiggler, the energy loss will be $26 \mathrm{keV}$. Accordingly, if six wigglers are included, the total loss per turn will be $330 \mathrm{keV}$ (probably only five wigglers will be used because of machine service requirements in one straight section). With a beam current of one ampere, the total $x f$ power, fncluding cavity losses, will approach $500 \mathrm{~kW}$. Peak voltages on each of two cavitles can be as much as $500 \mathrm{kV}$.

To minimize operating costs, the power ampliflers which drive the rf accelerating cavities must operate at high efficiency and must have long lives. High power tubes are avallable with reasonable characteristics, yielding power of the order of $500 \mathrm{~kW} \mathrm{cw}$, up to about $100 \mathrm{MHz}$. At this frequency, tube efficiercy fs beginning to deteriorate and 1 t seems wise to choose an operating frequency of about $50 \mathrm{MHz}$, corresponding to a harmonic number of 24 .

The accelerating cavities will be simple cylindrical resonators with a smal? amount of capac1ty loading to reduce the1r overall size. Tuning will be necessary to compensate for beam loading and thermal effects; this will be accomplished by a mechanically varlable capactative tuner. The tuning range required w1ll be of the order of $100 \mathrm{kHz}$. 


\section{Vacuum System}

An ultravacuum will be required; it will be necessary to achleve pressures of $10^{-10}$ Torr without beam and $10^{-9}$ Torr with full beam. Experlence with storage rings elsewhere Indicates that satisfactory performance can be expected from an extruded aluminum chamber with an integral water cooling channel and with distributed tieantum pumping to collect the large quantities of gas liberaced when the wall is bombarded by radiation. Vacuum chamber cross sections sultable for Inclusion in bending and quadrupole magnets are shown in Figures 8 and 9 . The entire chamber will be surrounded by heaters fo: 'akeout to tamperatures of $150-175^{\circ} \mathrm{C}$. Experience at SPEAR has shown that this process is aeeded ratter infrequently but is essential occasionally. Spectal care in design of the cooling system is required where side pipes are included for transmission of radiation te experimental apparatus. Also, where superconducting components are used, as in the high $f$ seld wigglers, low temperature components must be protected from radiation. In general the angular deflections in high field wigglers will be swall enough that the radlation will travel an appreclable distance before Impingling on the wall. Speclal attention will have to be given to portions of the chamber on the Inner circumference just downstream from the wigglers. 

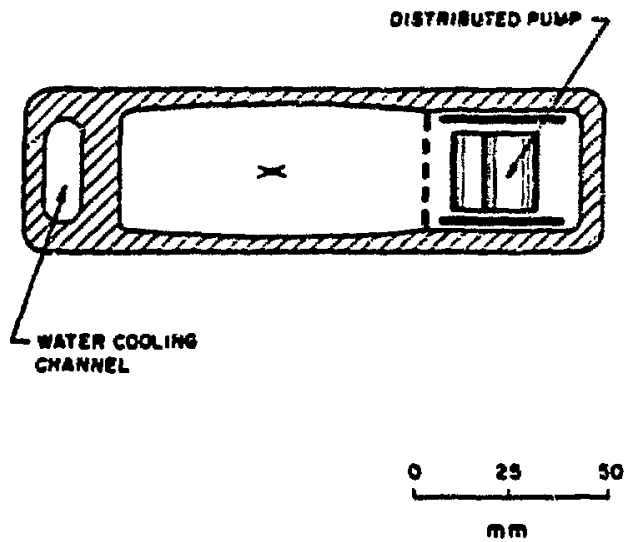

VACUUM CHAMBER

BENOIHG MAGNET

EIGLRE 8
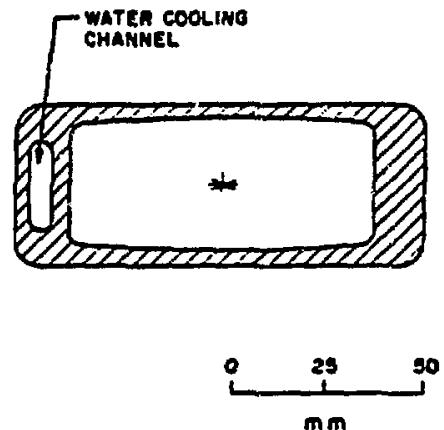


\section{Princlpal Parameters and Other Des1gn Data}

The ring of six superferiods would have the following paramecers:

Leggth of one arc

Length of Insertion

Circumference

$R=C / 2 \pi$

p (In BB)

$R / \rho$

Bp

B

Number of bending magnets

Weight of each

Power at $2 \mathrm{GeV}$

Number of quadrupoles

Number of sextupoles

Number of wigglers

Max. wiggler bends (at $1.5 \mathrm{GeV}$ )

Max. wiggler field
$14.7 \mathrm{~m}$

7.7 m

$134.5 \mathrm{~m}$

$21.4 \mathrm{~m}$

8.17 m

2.62

$1.5 \mathrm{GeV} 2.0 \mathrm{GeV}$

50.1

$66.8 \mathrm{kG}-\mathbf{m}$

6.13

$8.17 \mathrm{kG}$

48

300016

$450 \mathrm{~kW}$

66

36

5 or 6

$3.7^{\circ},-7.4^{\circ}, 3.7^{\circ}$

$40 \mathrm{kG}$

Dynamic Characteristics of the beam would be approximately:

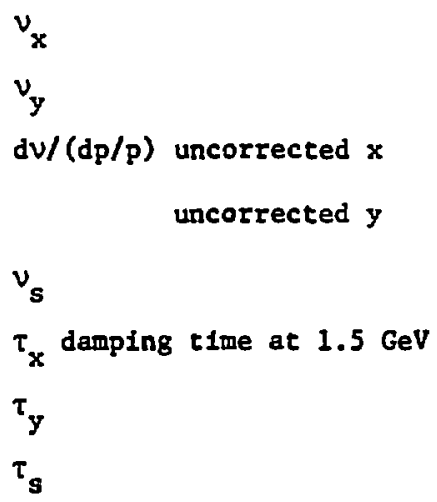

$\tau_{y}$

$\tau_{s}$

9.5 msec

9.5 msec

4.7 msec 
Dynamic Characteristics of the beam (cont'd.)

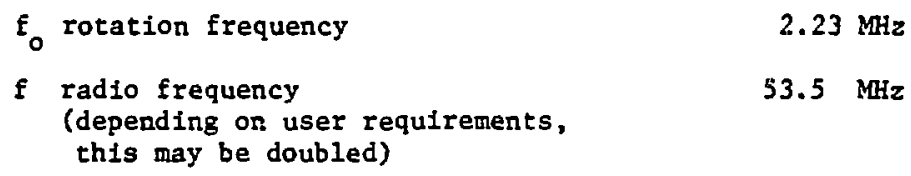

h harmonic number

$24(48)$

Power to beam in $\mathrm{w} / \mathrm{mA}$ or $\mathrm{kw} / \mathrm{A}$ :

RIng Transverse Wigglers Total

$\begin{array}{lrrr}1.5 \mathrm{GeV} & 55 & 88 & 143 \\ 2.0 \mathrm{GeV} & 173 & 155 & 328\end{array}$

No. of cavities

Peak voltage, each

$350 \mathrm{kv}$

Touschek life (small bunch lengthening)

e $1 \mathrm{~A}, 1.5 \mathrm{GeV}$

1 hr.

\section{The $700 \mathrm{MeV}$ Ring}

A small $700 \mathrm{MeV}$ ring, Intended for users interested in the ov region of synchrotron radiation, has also been designed. Its general layout is shown in Figure 10. Similar to the $2 \mathrm{GeV}$ Iing, its lattice configuration is aimed at minirizing the electron beam emittance. The ring consists of four achromatic arcs connected by straight sections. The straight sections, which are designed as matched insertions, will be used for wigglers of elther the conventional or the helical type. They will also be used for frijection and rf accelerators. The maximum field in the bending magnets in $\sim 12 \mathrm{kG}$. The horizontally focussing quads QF between the two dipoles in each arc make the horizontal dispersion function zero outside ares. This function reaches a maximum of $\sim 1$ in in quadrupoles QF. The triplets adjacent to the arcs focus the beam at the center of the straight section. Depending on the settings of the triplets two sets of 6-values (low or high) can be obtained at the insertion centers. 


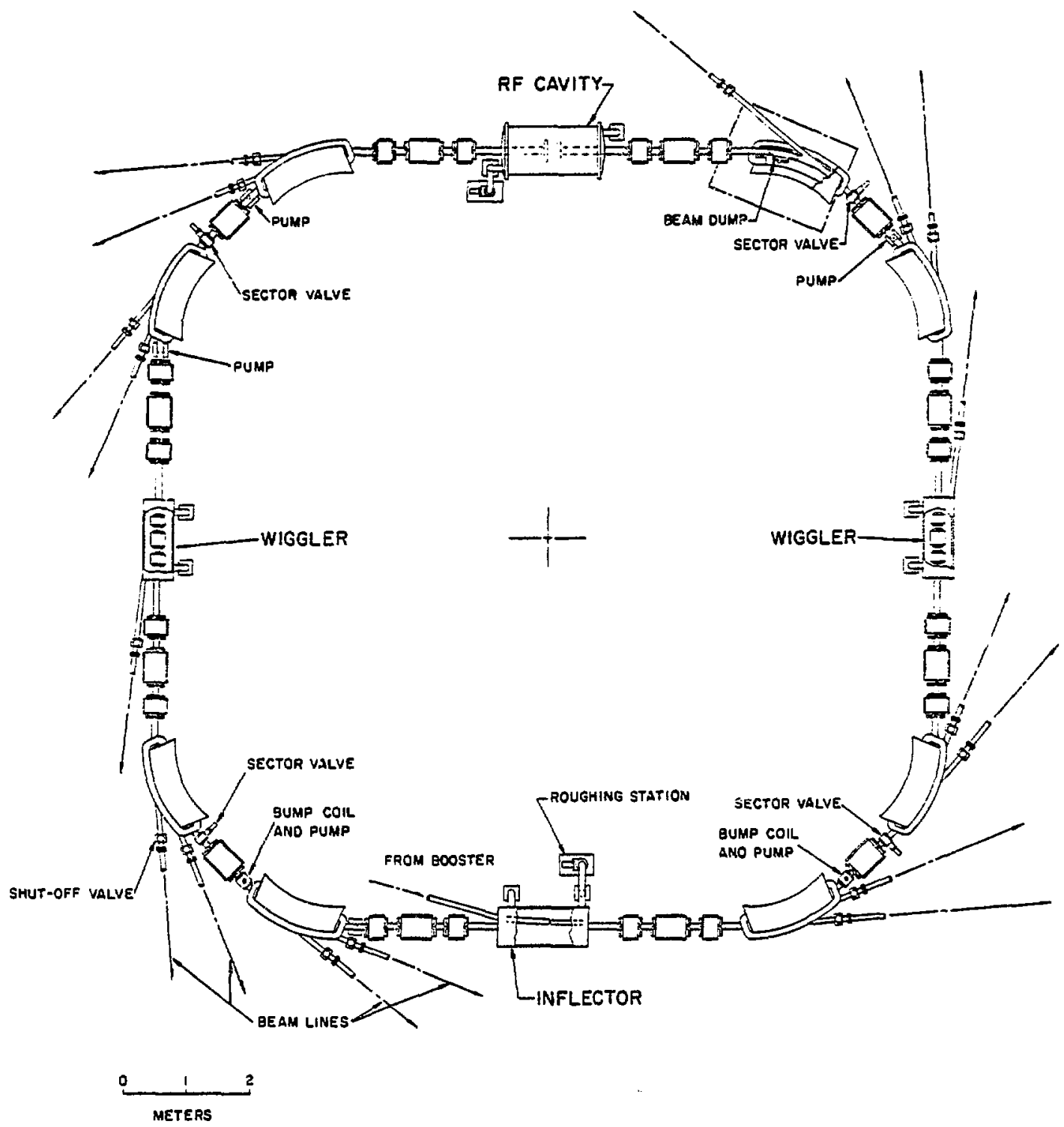

$700 \mathrm{MeV}$ RING 
For conventional wigglers Iow $\beta$ values are desirable to achleve high beam brightness, while the high $B$ values are necessary for an optical match of the helfcal wiggler to the ring. High $\beta$ values are also required for injection to avoid an excessively thin septum in the injection magnet. Sextupoles SF and SD will control the chromaticity of the ring. $B$ and $X_{p}$ functions are shown in Figure 11. A summary of the basic machine parameters is given in the Table at the end of this section.

The energy loss per turn in the ring (not including wigglers) is $11 \mathrm{KeV}$ at $700 \mathrm{KeV}$. It will be supplied by a $50 \mathrm{MHz}$ rf cavity with a gap voltage of $100 \mathrm{kV}$. Although an adequate quantum lifetime can be achieved with much lower voltage levels, a gap voltage of $100 \mathrm{kV}$ will give a sufficiently large rf bucket to ensure an acceptable Touschek lifetime. With a circulating beam current of $1 \mathrm{~A}$, taking into account bunch lengthenting, a beam life of $\sim 2$ hours can be expected. The total if power, including cavity losses, will be ? $20 \mathrm{~kW}$.

\section{Principle Parameters and Other Design Data}

The ring of four superperiods would have the following parameters:

$\begin{array}{lc}\text { Length of one arc } & 4.50 \mathrm{~m} \\ \text { Length of Insertion } & 6.50 \mathrm{~m} \\ \text { Circumference } & 44.0 \mathrm{~m} \\ R=C / 2 \pi & 7.0 \mathrm{~m} \\ \rho \text { (In BB) } & 1.90 \mathrm{~m} \\ R / \rho & 3.67 \\ \text { B } & 0.7 \mathrm{GeV} \\ \text { B } & 23.34 \mathrm{kG}-\mathrm{m} \\ \text { Number of bending magnets } & 12.3 \mathrm{kG} \\ \text { Weight of each } & 8000 \mathrm{lbs} .\end{array}$


Parameters for the ring of four superperiods (cont'd.)

Power at $0.7 \mathrm{GeV}$

$220 \mathrm{~kW}$

Number of quadrupoles

Number of sextupoles

Number of wigglers

2

Dynamic characteristics of the beam would be approzimately:

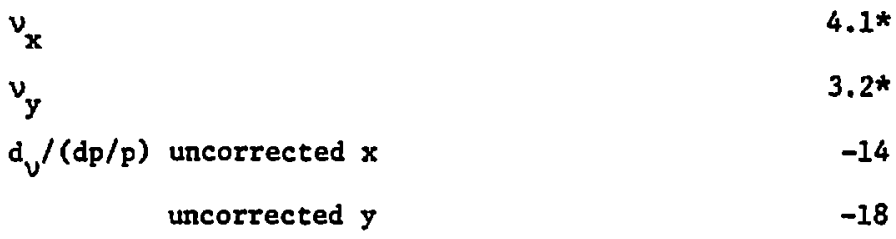

$v_{s}$

0.002

$\tau_{x}$ damping time at $0.7 \mathrm{GeV}$

20 msec

$\tau_{y}$

$18 \mathrm{msec}$

$\tau_{s}$

9 msec

$f_{0}$ rotation frequency

$6.8 \mathrm{MHz}$

$f$ radio frequency

(depending on user requirements,

$53.5 \mathrm{MHz}$

this may be doubled)

$h$ harmonic number

Power to beam in $\mathrm{w} / \mathrm{mA}$ or $\mathrm{kw} / \mathrm{A}$ at $0.7 \mathrm{Gev}$

No. of cavities

Peak cav1ty voltage

$100 \mathrm{kV}$

Touschek life (small bunch lengthening)

(e) $1 \mathrm{~A}, 0.7 \mathrm{GeV}$

$2 \mathrm{hr}$.

* Assumes two low $B$ and two high $B$ insertions.

\section{Injection System}

The Infection system will consist of a $50 \mathrm{MeV}$ IInac and a $700 \mathrm{MeV}$ booster synchrotron. This combination is required to achieve circulating currents of $1 \mathrm{~A}$ in both the $700 \mathrm{MeV}$ and the $2 \mathrm{GeV}$ rings. The radial 


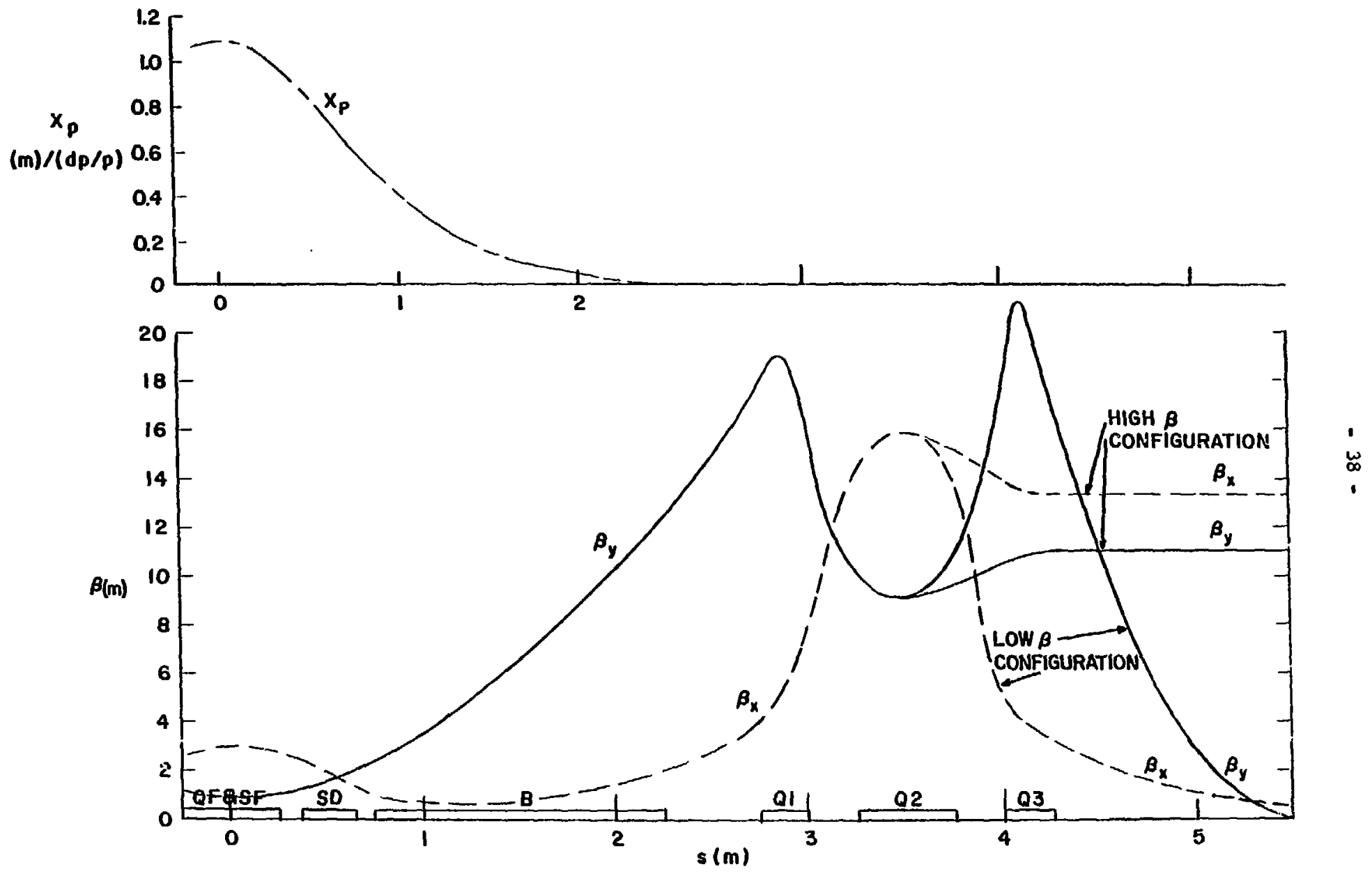

FIGURE 11. 1 AND $X_{p}$ FUNCTIONS, 700 MEV RING 
betatron motion in the booster has to be damped if hellcal wigglers are to be used in confunction with the storage rings. This is because the vacuum chamber aperture may be constricted to as little as about $1 \mathrm{~cm}$ at the location of the wigglers.

A simple separate function booster has been designed consisting of two $180^{\circ}$ arcs, each contain:lng 3 FODO cells. The lattice is shown In Figure 12. Straight sections, $1.5 \mathrm{~m}$ in length, connect the two arcs. These are inserted between the two halves of a cell defocussing quadrupole. In this way, the $x_{p}$ function stays matched while the periodic variation of the $\beta$-function in the cell wll be somewhat perturbed. The maximum values of $\beta_{x}$ and $\beta_{y}$ are 11.4 and $7.5 \mathrm{~m}$. The magnetic field in the dipoles is $8.15 \mathrm{kG}$ at $700 \mathrm{MeV}$. One of the straight sections will be used for injection and for rf acceleration, the other for ejection.

A $~ 250 \mathrm{MHz}$ rf system results in a harmonic number of 6 . Injection and ejection kicker demands can be greatly reduced by chopping the Iinac beam and filling only one or two out of the six rf buckets. With a $20 \mathrm{~mA}$ IInac current and a $0.75 \mathrm{sec}$ acceleration cycle $(0.25 \mathrm{sec}$ flat top) It w11l not take more than 9 and 3 minutes to fill the $2 \mathrm{GeV}$ and $700 \mathrm{MeV}$ ring, respectively. The energy loss per turn in the synchrotron booster is $7.5 \mathrm{kV}$ at $700 \mathrm{MeV}$.

$\begin{array}{lc}\text { The basic booster parameters are as follows: } \\ \text { Energy } & 700 \mathrm{MeV} \\ \text { Circumference } & 34.2 \mathrm{~m} \\ \text { Revolution Time } & 0.11 \mathrm{\mu sec} \\ \text { Bending Radius } & 2.86 \mathrm{~m} \\ v_{x} & 1.72 \\ v_{y} & 1.59 \\ \text { Momentum Compaction Factor } & 0.45 \\ \text { Horizontal Damping Time } & 0.02 \mathrm{sec}\end{array}$


The basic booster parameters (cont'd.)

Vertical Damping Tfme $0.02 \mathrm{sec}$

Longitudinal Damping Time*

Horizontal rms Emittance

$\sim 3 \times 10^{-7} \pi \mathrm{m}-\mathrm{rad}$

Harmonic Number

6

* Assumes parallel edge bending magnets. 


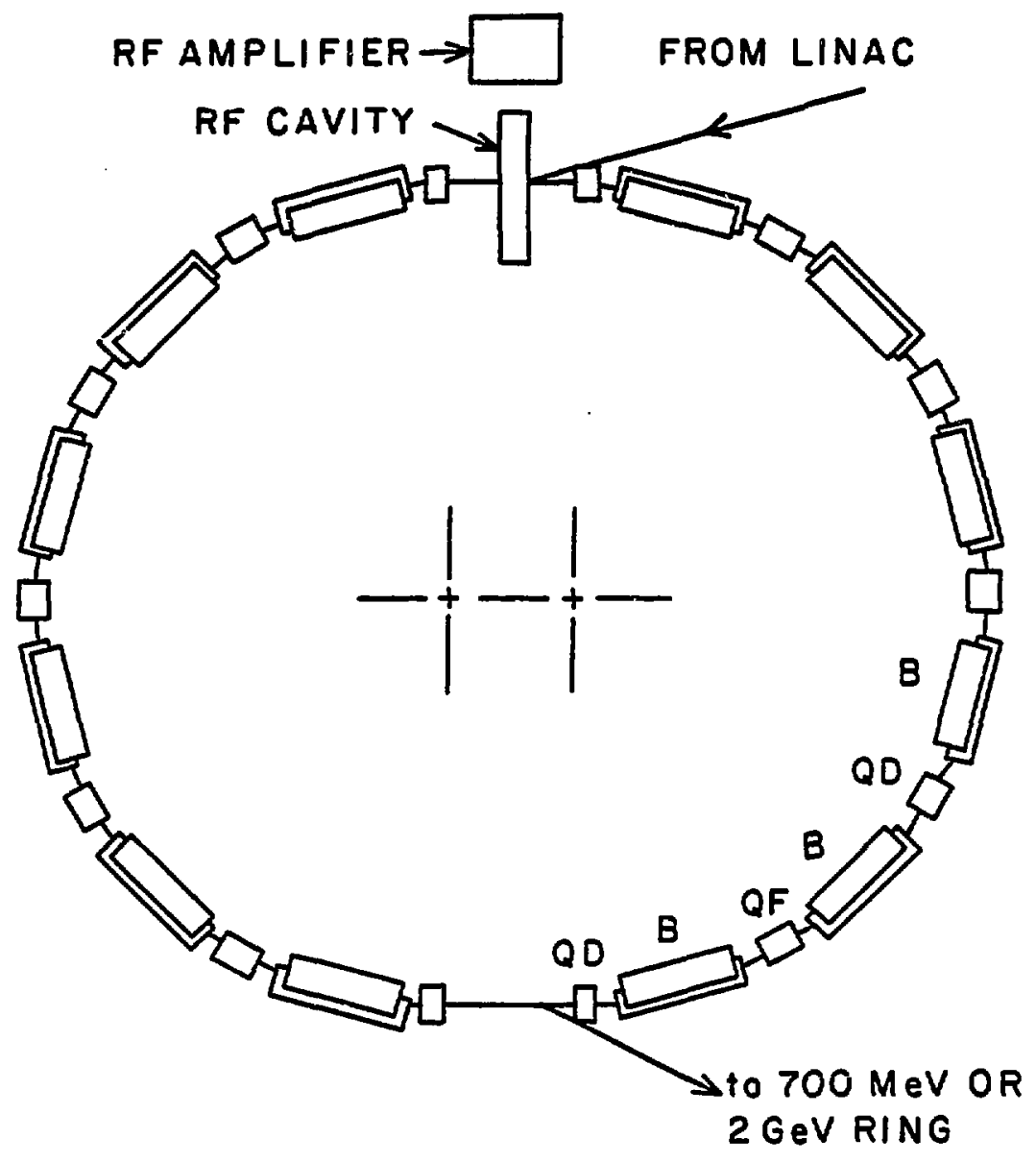


IV. BUILDINGS AND UTILITIES

The speclalized propertles of the synchrotron light source and of its research program set the requirements of the buildings and services. The most significant of these are as follows:

a. A very stable base for the storage rings and the optical beam lines. This is probably the single most critical techntcal requirement of the structure.

b. An air temperature of about $75^{\circ} \mathrm{F}$ which must be maintalned with small but reasonable variation to match the mean cooling water temperature.

c. A controlled humidity level so that the dew point will always be well below the cooling water inlet temperature.

d. Components are of small unit weight. This affects the design of the base and material handling methods.

e. The electrical power demand is relatively small.

f. Control of cooling water temperature is to be maintained for thermal stability of the storage rings.

8. Beam lines and research apparatus are of small size and weight with low power and cooling water demands.

h. Vibration must be minimized by separating rotating machinery from the ring building.

1. Attached auxiliary space is to be provided for control rooms, laboratories and offices.

These requirements can be well satisfied by a modular, prefabricated or "pre-engineered" industrial type structure erected on a thick reinforced concrete slab. The area inside the storage rings will hold the injector and auxiliary, mostly electrical, equipment. Corners of the rectangular structure will be utilized for some long beam lines, staging 
areas for experiments, and storage of equipment not in service. Ductwork and primary services will be suspended overhead from the beams and purlins. Since ring parts and shield blocks will weigh no more than $4000 \mathrm{Ib}$. each, they can be handled by standard floorrunning equipment. A wing $\sim 6000$ sf will house the control rooms, laboratories and some offices. Additlonal laboratory and office space will be provided in the existing Accelerator, Blology, Chemistry and Physics Departments bufldings. An Industrial type structure on a separate foundation will house all rotating service machinery.

\section{A. Foundation Base}

The overburden will be scraped away to compacted sand. A thick reinforced concrete slab will be placed in a continuous pour without joints or trenches. The concrete membrane wlll smooth small Irregularfties and spread the loads: Long span stability (greater than 10 to $20 \mathrm{ft.}$ ) 1s provided by the sand. The glaclally compacted sand underlying Brookhaven National Laboratory has proved to be a stable and predictable base. If loads are kept below a few thousand psf, preferably below 3000 psf, the sand behaves like an elastic medium with some hysteresis. There are no indications of heaving or quasi-liçuid behavior. The soll mechanics properties have been measured to high accuracy at the AGS which is nearby the proposed site. A check will be made to verify that soll conditions are similar.

Loading over an appreclable area gives a prompt settlement of 80 mil per 1000 psf with a rebound of about $2 / 3$ that when the load is removed and a reloading curve parallel to the rebound curve. Most of the loads imposed by this factlity will produce deflections of a few mils. The $2 \mathrm{GeV}$ ring shfelding will welgh about 8000 1b. per circum-

ferential foot. If a sector of this shielding is removed, the ring will 
rebound 10 to $25 \mathrm{mils}$ (depending on length of the sector) and will recover to within 2 or 3 ails when the shielding is replaced for operation. The only alignment problem anticipated could come from a heavy snow load. Once every few years the snow load on the roof w11 approach or exceed 10 psf. Forces transmitted through the columns could then disturb the ring alignment and interfere with operation until the snow is melted or removed. Removal of the load will restore alignment well within the range of the correcting coils. Since such a heavy storm would disrupt operation anyway, there is no justification fo: incurring the heavy expense of incorporating a long span roof structure to avold this problem.

Years of experience with the AGS indicate that realignment of the rings will be required only at long intervals. Heavy loads in this facllity will seldom be shifted. After a year or two, from pour, the anneal temperature cycling beneath the slab will be very small. Provision for alignment will be made by casting pipes in the internal shield wall for access by aligmment tools. These small rings can then be aligned to high precision with radius tapes, templates and optical levels.

\section{B. Structure}

The most economical structure is a pre-engineered shell with wodules about 25 by $50 \mathrm{ft}$. The locations of support columns have been taken Into account in the machine design and do not offer serious obstructions. Panels for sidewalls and roofs will be well insulated and a thick impervious mat will insulate the slab edge from the grade beam. These structures will be ordered complete with conventional HVAC, sprinklers, lighting, partitions, doors, toilets, etc. An eave height of $20 \mathrm{ft}$. will give about $17.5 \mathrm{ft}$. net clearance under the eave and about $25 \mathrm{ft}$. clearance 
at the ridge. The office and laboratory wing will be attached to the sides of the ring housing, and will be furnished with interior partitions and acoustical hung cellings. The accelerator bullding will have a sheet metal sidewall liner but the roof steel will be left exposed so that services can be suspended from it.

A mechanical equipment building about $4000 \mathrm{sf}$ wlll be erected on a separate foundation to minimize vibration in the main slab. This building will contain the chillers, pumps, heat exchangers and compressors. Adjacent to it will be located the substations and evaporative coolers.

C. Power

The peak demand is estimated as follows:

$\begin{array}{lc}\text { Magnet systems } & 1700 \mathrm{kw} \\ \text { Rf systems } & 1100 \\ \text { Small ring systems } & 100 \\ \begin{array}{l}\text { Research apparatus } \\ \begin{array}{l}\text { Mechanical services } \\ \text { and building }\end{array}\end{array} & 200 \\ \quad \text { Peak demand } & 41000 \\ \end{array}$

The incoming feeder will be $13.8 \mathrm{kv}, 3-p h a s e$, and $10 \mathrm{Mva}$. Major rf power supplies using about $1000 \mathrm{kw}$ will be supplied at $13.8 \mathrm{kv}$. The other loads will be supplied by two $13.8 \mathrm{kv} / 480 \mathrm{v}$, 3-phase $2500 \mathrm{kva}$ unit substations packaged with load disconnect and secondary breakers. Four heavy bus duct feeders will route to three diatribution centers in the rittgs and one in the mechanical equipment building. Each distribution center will contain a $100 \mathrm{kva} 480 / 120-208 \mathrm{v}$ transformer for low power apparatus. An additional 120/208 v transformer will be located in the laboratory wing for power and lighting. Power for experiments will be distributed in bus duct hung on the outer periphery of the ring and shielding. Refer to Figure 13 for $480 \mathrm{v}$ feeder schematic. 


\section{Cooling}

Evaporative coolers will supply water through a closed circuit to the high power if systew, the chillex condensers and the HVAC condensers. Total peak demand, divided among four units, will be about 9 million Btu/hr. The dew point during wuch of sumer is too high for cooling the magnet systems and vacuum chambers. For this reason about $600 \mathrm{~T}$ of chillers will be installed to provide a wean temperature of $75^{\circ} \mathrm{F}$ and rise of $15-18^{\circ} \mathrm{F}$. When the dew polnt is sufficlently low, control valves will divert load from the chillers to the svaporative coolers. Demineralizers will be provided in the closed water circuits to maintain a high degree of water purfty. Major supply and return plping will be routed to a few distribution points from which prefabricated manifolds will feed the multiple couling connections. (See Figure 13.)

\section{E. Materlal Handling}

Unit parts of the rings and shielding will be kept to about $4000 \mathrm{1b}$. maximum. These parts can then be handled by a celescoping hydraulic boom crane operating on the slab. A fork iff will be captive Inside the $2 \mathrm{GeV}$ ring for materials transfer to the boom crane. Sectors will be kept clear of long beam lines to provide access, and one or two overhead monorails will be mounted as auxiliaries. Elimination of overhead crane coverage permits free use of vertical space for service risers and elimination of trenches in the slab. This not only reduces cost but aiso improves stability. Extensive material handling will not of ten be required during operation of this factlity. The beam lines and experi-. mental equipment are light in welght and will be installed with normal laboratory handling equipment. 


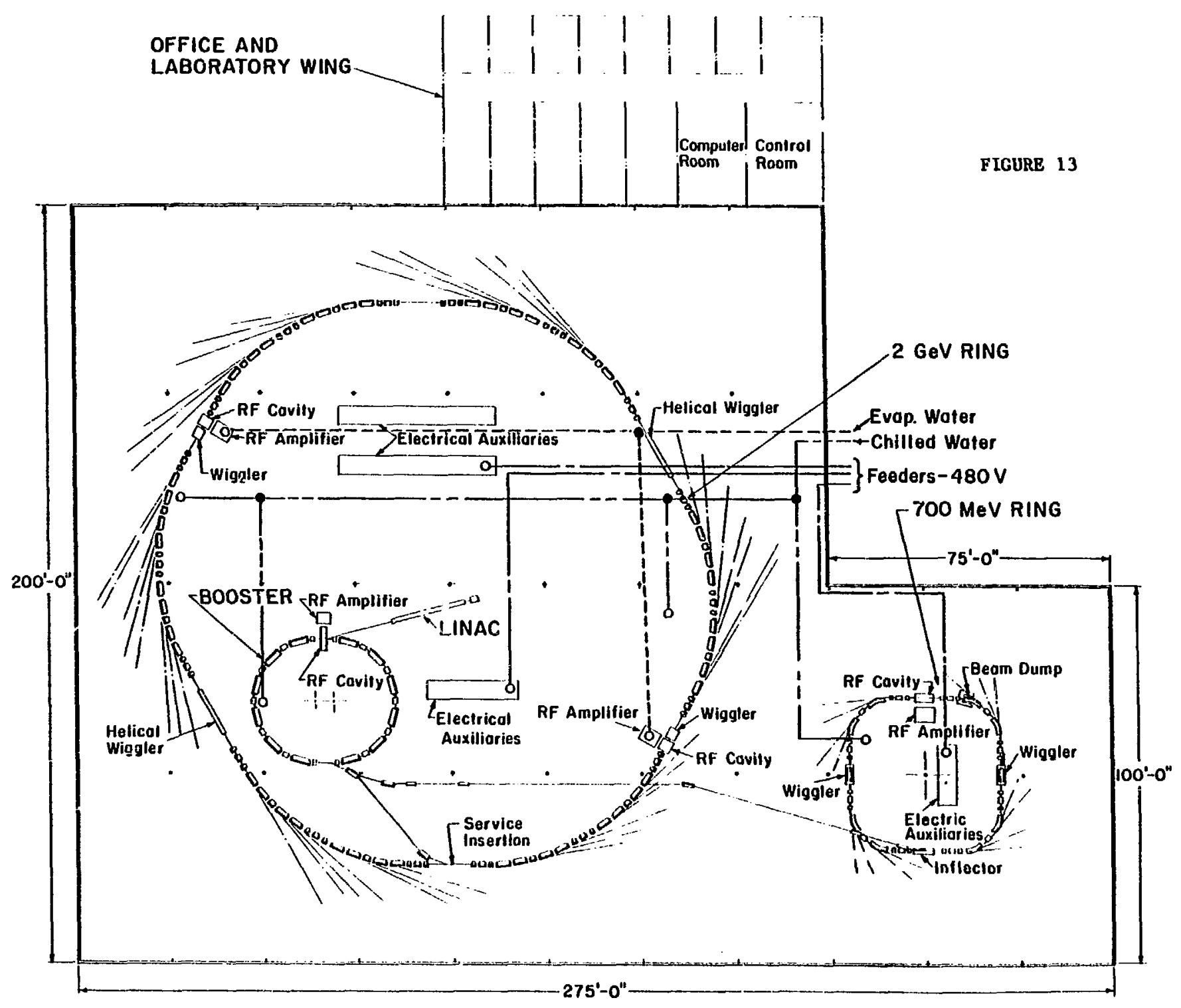




\section{F. Sita}

The site envisioned at present is south of the Instrumentation Diviston building and has close access to the varlous services and utflitles. If future detalled examination of soll and drainage, or other considerations, should so warrazt, another site can be selected from the several alternate locations also considered at this stage. 
v. OTHER INFORMATION DEVELOPED IN CONCEPTUAL DESIGN

A. Shielding

It is important that experimenters have good access to their equipment during normal operation of the stored beam. There will be occasions where raquirements on having a first optical element close to the point of the light source, and perhaps aven in the main vacuum of the machine imply low accessibility for the experimenter. The shieldIng Indicated below further increases the distance of closest approach of the first highly accessible element on an experimental beam line. The shfelding is, of course, essential to allowing general access to the experfmental floor and radiation levels will be monitored during machine operation. There are a variety of sources of radiation requiring shielding. For example, during a run some of the electrons are spilled from the beam and collide with vacuum chamber walls and adjacent hardware. Much of the attendant radiation, except for photoneutrons, will be satisfactorily contained by a 6-8 cm thick belt of lead external to the vacuum chamber of the $2 \mathrm{GeV}$ ring. There will be photoneutrons with energles ranging up to roughly $60 \%$ of the electron beam energy, however, and these require concrete shielding. Aspects of this problem are considered in the three paragraphs which follow.

\section{Catastrophic Spills}

While there will be a well-shielded beam dump it is concelvable that the beam wight be accidentally dumped somewhere else in the vacuum system. The consequences of dumping a $1 \mathrm{amp} 2 \mathrm{GeV}$ beam can be estimated by scaling the calculations ${ }^{1}$ of Alsmiller and coworkers for the photoproduction of neutrons and for their shielding. Assuming two feet of concrete

1. T. A. Gabriel and R. G. Alsmiller, Jr. ORNL-4443 (unpublished Oak RIdge National Laboratory 1969 (and R. G. Alsmiller, Jr. and J. Barish, Particle Accelerators 5, 155 (1973). 
shielding, as allowed for at present in construction plans, the maximum dosage is associated with standing just outside the shielding at the point where the beam is dumped. This dosage is found to be less than $100 \mathrm{mRem}$. Its low value is largely a consequence of the fact that only a few, 1.e. $\sim 3 \times 10^{12}$, electrons are stored in a 1 amp beall in the 2 GeV machine.

\section{Continuous Beam Spill}

Electrons are lost from orbit in the course of a normal beam run. Some will be picked up by a beam scraper and a substantial fraction of the initial beam will go into the beam dump at the end of the run, but some wili be lost around the ring during the course of the run. Assuming a month of twenty 9-10 hour shifts and that half the electrons present after loading are lost by spillage round the $2 \mathrm{GeV}$ ring, the monthly dosage immediately outside the concrete shielding will be less than half that associated with a catastrophic spill. Inasmuch as a worker will normally not spend his entfre month leaning on the machine shielding, but will on the average be further away, the normai monthly dosage from continuous spillage will be very wuch smaller. We estimate a typical dosage from this source to be of the order of a mRem per month on the $2 \mathrm{GeV}$ machine.

\section{Splllage on the $0.7 \mathrm{GeV}$ Ring}

Radiation levels due to spillage will be an order of magnitude lower on the $0.7 \mathrm{GeV}$ ring. First, there are fewer electrons stored In the ring: granted a ring circumference which $151 / 3$ as great, $1 / 3$ as many electrons are stored in the ring at some given machine current. Secondly, the photoneutron dosage assoclated with stopping an electron, scales roughly with the electron's energy. This provides another factor of $1 / 3$ on going from the $2 \mathrm{GeV}$ to the $0.7 \mathrm{GeV}$ ring. 


\section{Beam Loading}

Radiation levels at the time of injecting a beam into a ring and bringing it to full energy depend in detall on loading procedures. In general, the radiation levels are slgnificantly higher during this time and 1 t has been the practice at some synchrotron radiation facilities to clear the experimental floor surrounding the ring of personnel during loading (1oading time is the order of minutes on the proposed facility). This is Inconventent and, given the shlelding provided the two rings, efforts will be made to develop loading procedures which will let personnel stay on the experimental floor. Requirements on the final beam and hence on Its loading may not allow this, however.

\section{Linac and Booster Synchrotron}

The $50 \mathrm{MeV}$ linac will require some concrete shielding, of the order of two foot thickness, cownstream and in the beam transport region. The $700 \mathrm{MeV}$ synchrotron will have a 50 milliamp current and $3 / 4 \mathrm{sec}$ cycling period. It will require concrete shielding round the Injector and in local regions where losses are found to be high. Significant shielding of personnel comes from the fact that these two devices will be located inside the $2 \mathrm{GeV}$ ring.

\section{Beam Lines}

The photon beam lines penetrate the main shielding of the rings and this introduces several potentlal radiation hazards. Electrons straying outside the main orbit may hit the vacuum walls upstream of the beam port at points In view of the port where neither the lead nor the concrete shlelding intervene. The area of wall in view can be greatly reduced by detailed shaping of the vacuum chamber upstream and by the Introduction of collimators in the beam line. Electrons hitting the vecuum wall Immediately downstream of the port can also produce radiation which, after going through a thin layer of shielding, also enters 
the beam line. Collimators also reduce this effect. Permanent magnets, placed on the beam line, can be used to sweep out any charged particle. Procedures will be established to keep personnel out of the photon beam lines at all times both against exposure to the prifary synchrotron radiation beams and to any other small amounts of radiation coming down the pipes. The effects of scattering these radiations off axis either due to residual gas or to optical elements in the beam lines will be monitored and local shielding employed when and if it proves necessary.

\section{B. Wigglers}

Design of the bending and focussing lattice of the ci:cular portion of a storage ring has limitations imposed by the requirements of stability and small emittance. Momentum dispersion in the bending magnets increases the $x$ dimension of the electron beam; double focussing in $x$ and $y$ Is difficult to achieve; and the ratio $\mathrm{E} / \mathrm{B}$ (that is, the radius) is fixed. In an insertion region between the arcs the momentum dispersion can be virtually zero; and strong magnetic lenses can give a double focus of the beam. A short triple dipole magnet (transverse wiggler) placed in the insertion will thus produce radiation from a very small source with little adverse effect on the electron beam elsewhere round the ring. There is also much interest in possible application of the helical wiggler. A helical, small bore magnet can produce circularly polarized radiation on axis with very high flux in a narrow spectral range. This radiation can be advantageous for several classes of experiments. Preliminary studies indicate that the helical wiggier can probably be used on a storage ring. 


\section{Transverse Wiggler}

Flelds of 40-60 kilogauss car readily be generated in superconducting windings. Using a set of split solenoids, the electron orbit undergoes a zero net deflection upon passing through the wiggler. The solenoid colls are located above and below the orbit, separated by a suffictent distance to allow passage of the beam and transmission of the emitted radiation. The critical wavelength, $\lambda_{c}$, of the spectrum from a $2-\mathrm{GeV}$ electron in a field of $40 \mathrm{kilogauss}$ is about $1.2 \mathrm{~A}^{\circ}$. If the fleld Is increased to $60 \mathrm{kilogauss}$ the critical wavelength will be reduced to about $0.8 \AA$ Located at a focal point of a low emittance storage ring, this wiggler would give the smallest and brightest $x$-ray source available with present technology.

Wigglers, if need be, can also produce spectra at longer wavelengths in high energy rings. In the $2-\mathrm{GeV}$ ring, for example, where the radiation from the orbits in the arc bending magnets has a $\lambda_{c}$ of about $6 \dot{A}$, spectra peaking at much longer wavelengths could be obtained by running wigglers at low ffelds. If, for example, a spectrum with $\lambda_{c}=40 \AA^{\circ}$ is desired, it could be obtained by running a wiggler with fields of about 1.2 kilogauss. Such wigglers would require much longer arc bends than in the high fleld case, and one could not simply run a $40 \mathrm{~kg}$ unit down to such a low fleld. A different design would be required.

The superconducting colls of a high field wiggler will each require about 3 million ampere turns. In the colls themselves there will be no losses so the only demands on the cooling system will follow from lead losses and from direct thermal conduction through the wall of the Dewar system in which the coils are enclosed. It is est1mated that about 20 Ifters of hellum per hour will be evaporated. The 
losses can be reduced by short circuiting the coils and operating them In the persistent superconducting mode. Dahl and Sampson (BNL Report 20079) have done preliminary studies of such a device and their calculated field distribution is plotted in Figure 14. The coils were designed to be wound from the wide braided conductor utllized generally in the BNL superconducting accelerator magnet program. The calculations assumed an air core design, although the final device will most likely incorporate an iron yoke, which can further enhance the fleld strength, tailor the field shape somewhat, and help support the coils against the considerable magnetic forces. With a $35 \mathrm{kG}$ deflecting field on the magnet axis, for example, the peak field is $49.6 \mathrm{kG}$, and occurs on the inner surface of the main winding.

Such transverse wigglers will be devised to work within specific ranges of field strengths. The storage rings can be operated with such a device elther turned on or off. The optical properties (beam position and source size) of the electron orbit at other radiation ports on the ring will not be significantly affected when such a wiggler is turned on.

\section{Helical Wigglers}

The helical wiggler is a vartant of the "free electron laser" evalved at Stanford and recently tested using a beam from one of the Stanford electron 1inacs. In this device a transverse magnetic field is generated whose direction rotates continuously with distance along the axis - the axis belng coincident with the axis of the electron beam.

Such a field can be generated by excitation of an open hellcal winding. In the open spaces between the turns of one winding, a second is wound and is excited with current flowing in the direction opposite to the current in the original winding. This current 
$J=18 \mathrm{kA} / \mathrm{cm}^{2}$

$Y(\mathrm{~cm})$
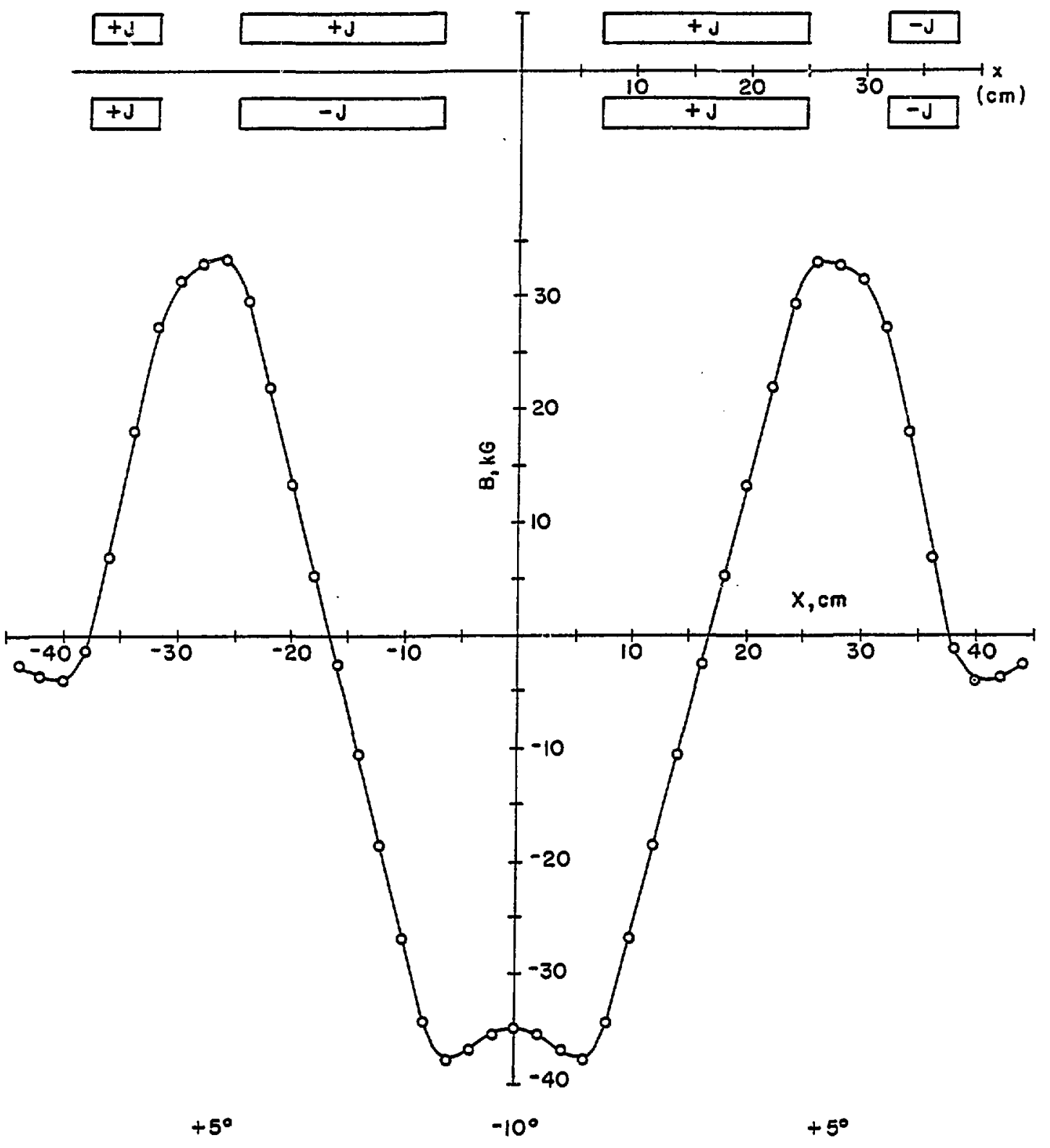
combination produces a field pattern with a zero axtal component on the axis and with a transverse cemponent which rotates with the same period as the pitch of elther hel1x. The transverse field varies slowly near the axis, then increases rapidly as the winding is approached; this varlation places severe limfts on achievable transverse fields and on the useful thickness of the winding. For example, to obtain transverse fields of 6 kilogauss in a helix of pltch $2 \mathrm{~cm}$, the maximum inner diameter of the wlggler will be about $I \mathrm{~cm}$ and current densities of the order of 50,000 amperes $/ \mathrm{cm}^{2}$ will be required. Evidently only superconducting windings will be usable. The electron orbits in the fleld patterns for such a device were traced in a number of computer runs and were found to agree with orbits derived froin an approximate form of the equations of motion. The primary motion is helical with an orbit radius that is a small fraction of a millimeter and a pitch which is the same as that of the transverse field. The Instantaneous axis of the helix is tangent to a sinusoldal "betatron osc1llation" which lies in a plane through the axis of the wiggler. For a range of possible wiggler parameters the frequency of this oscillation is two to four orders of magnitude slower than that of the helfcal motion. Its phase and amplitude are determined by Initial conditions. By a sultable (non-zero) cholce of inftial transverse velocities the amplitude of the betatron oscillation can be reduced to negligible values; with this correction all electrons, including those off axis will pursue helical paths whose axes are parallel to the wiggler axis and whose radif are almost identical.

The spectrum emitted by this wiggler will be peaked at a wavelength which is approximately the pitch of the helix divided by $v^{2}$ where $v$ is the ratio of the electron energy to its rest energy. Thus, 
for a 2-GeV electron in a hellx of 2-cm pitch, the spectrum will be peaked at about $12 \AA$. The fractional bandwidth of the spectrum will be approximately $1 / N$ where $N$ is the number of turns in the heifcal winding.

The primary helical motion of the electron will have such a small dlameter that its pitch angle will be of the same order as the angular width of the radiation cone emitted by the electron. Thus the radiation pattern emitted through the end of the wiggler wi.l be a cone whose outer edge makes an angle with the wiggler axis which is the sum of radiation cone angle and the pitch angle of the electron's helical motion.

The general behavior of electrons in the $20 \mathrm{MeV}$ range in a helical wiggler has been checked at Stanford. Whether or not such a wiggler can be Included in a storage ring has been studied at Brookhaven where $1 t$ has been concluded that, wath proper attention to Initial and final conditions at the wiggler, stable orbits can probably be maintalned. By coupling $x$ and $y$ motions of the orbit, the presence of such a wiggler adversely affects the optical properties of the electron beam elsewhere in the ring. However, such devices offer the possibiilty of circularly polarized light which is of some orders of magnitude higher flux, In the peak of its spectrum, than that avallable from conventional synchrotron radiation.

The properties of helical wigglers and the behavior of electrons therein heve been described recently in companion papers "A Short Perlod Hellcal Wiggier as an Improved Source of Synchrotron Radiation", by B. M. Kincald of the Bell Laboretories, and "Orb1ts and Flelds in the Helical Wiggler", by J. P. Blewett and R. Chasman of BNL. These papers have been submitted for publication in the Journal of Applied Physics. 


\section{Experimental Equipment}

Apparatus such as monochromators, detectors, data acquisition systems, and vacuum equipment for use in the photon beam lines emerging from the storage rings will require substantial expenditures; a fully Instrumented experfmental station costs several hundred thousand dollars. It is essential that a substantial investment be made for experimental equipment during the construction perfod. Some components of the beam line equipment will, in effect, be elements of the storage ring vacuum systems. Also, since the rings are to provide light sources of superior quality, it is important for equipment design work to proceed on a parallel and interactive basis with the detailed design of the storage rings.

Finished prototypes of experimental stations will be required for performance testing and diagnostic work at initlal start-up and during operational run-in. Finally, this perfod can be utilized for solving equipment development problems and for strengthening certain of the Instrumentation capabilities at the Laboratory needed for support of the facility.

The equipment funds included directly in the project construction budget will cover the high priority items needed to meet the objectives outlined above, and will provide a modest base of usable equipment when the facility becomes available. A substantial accompanying research and development effort will be required on some special items, however, and a sizeable capital investment must also be anticipated to activate additional stations and to meet the needs of an expanding research program. These R\&D and capital requirements are noted approprlately in Section VI.

In general, equipment for research with synchrotron radiation can be classified according to the spectral ranges used in experiments. This determines the type of monochromator (normal or grazing incidence, crysta1), 
local shielding requirements, vacuum equipment (Including ring vacuum protection), Interaction with ring geometry (small ring, large ring, arc source or stralght section). Even within a particular spectral region, however, there can be substantial varlations in equipment requirements for different types of experiments. In the hard $x$-ray region, for example, quite different types of spectrometers are needed for extended $x$-ray absorption fine structure (EXAFS), crystal diffraction, and small angle scattering. One must also take into account the rapld changes in instrumentation for synchrotron radlation research. Equipment is becoming increasingly sophisticated, as is always the case when a new tool comes Into use. Many changes can be expected over the years before the Brookhaven facllity becomes operational. These advances will, of course, be exploited in expurimental station designs.

In substantial measure, however, baslc requirements can be anticipated. New and improved monochromators, for example, w111 certain1y be developed, but the problems assoclated with providing maximum accessibility, stable and conveniently ajustable mounts, cooling (when necessary), etc. are subject to definition. Some development directions on the monochromators themselves can be foreseen, such as layered $x$-ray monochromators, for example. Faster energy sensitive detectors than those currently avallable are needed both for spectroscopy and, in some cases, simply for sorting out extraneous higher order wavelengths impinging on a detector. Simllarly, one would like higher resolution $x$-ray video detectors: a resolution of $1 \mu \mathrm{m}$, as compared with the $20 \mu \mathrm{m}$ surrently avallable, would be useful for, say, x-ray ropography. Position sensitive area detectors will be very 1mportant for several types of $x$-ray diffraction experiments. Studies in the VWV on surfaces w1ll require auxillary Instrumentation, such as Auger and LEED equipment for full characterization 
of a surface under study, mounted as integral components of an experimental station. A flexible computer system will be required for on-ine experimental control and data acquisition. The Brookhaven Computer Systems Group in the Instrumentation Division has considerable experience In this area and a study for such a system for the synchrotron light source has already been completed (avallable as an Informal Report, BNL 21109, April 1976).

Eight fully equipped experimental stations are proposed, divided between $x$-ray and $U$ usage. These would be installed in the insertions and In bending magnet regions. Although the exact cholce of the particular classes of experiment these stations w1ll serve and of details of instrumentation will be made later, as the time of utilization approaches, the nature of some parts of the Installations can be anticipated. There will probably be at least one station for angular dependent photoemission spectroscopy, a diffraction station employing the area detector and, of course, capacity for doing x-ray absorption spectroscopy; these, of course, will have computer capability. In addition to the eight complete installations, several beam lines w1ll be partlally instrumented, including monochromators, so as to expedite their activation early in facility operations. In a number of instances 1 will be desirable to have the first optical element, a mirror, crystal or grating, as close as possible to the light source. In some cases this w1ll necessitate placing the element inside the main machine vacuum. This will affect the vacuum and shielding design of the rings. The design of the vacuum chamber in the vicinity of a beam port can be complicated by the requirements of getting the light out whlle minimizling any perturbations on the electron orbits and any stray radiation going down the photon IIne. This is but one of the areas where design of the rings and design of the experimental lines interact strongly. 
It is important to emphasize that the full instrumentation effort (project, R\&D, and capital) is not intended simply to provide for limited inftial testing and experimentation but is expected to furnish the base of laboratory experimental capability on which the national program of the facility w11l rely. 


\section{COST ESTIMATES AND PROJECT SCHEDULES}

\section{A. Construction Schedule}

The design, procurement, and construction schedule for this project is shown on the following page.

Construction of the facility covers a period of three and a half years, including a six-month run-in period before the machine is ready to support an experimental program. To meet this schedule some preliminary and accompanying support work is required (see Section VI-D). If authorization is granted for construction at the beginning of FY 1978, the experimental program can begin in April 1981.

The preparatory work necessary is to make possible placing orders of critical path and long delivery items immediately upon authorization. This includes buildings, magnets, vacuum components and other major construction items.

\section{B. Manpower}

The project manpower requirements are shown in Table VI-1. The estimate is given by fiscal year and is broken down into two broad categories; professionals (scientists and engineers), and non-professionals (technicians, draftsmen, and others). The totals estimated are 132 manyears (62 professional and 70 non-professional) for ED \& I and 77 manyears (non-professional) for assembly and machine shop manpower associated with the storage rings and associated equipment. This estimate does not cover research and development activities, which are discussed in Section VI-D.

\section{Cost Estimate}

Details of the cost estimate are presented in summary Table VI-2 and in the detalled breakdown of Table VI-3. The estimate is based on current costs for labor and materials, with contingency and escalation 
$\nabla$

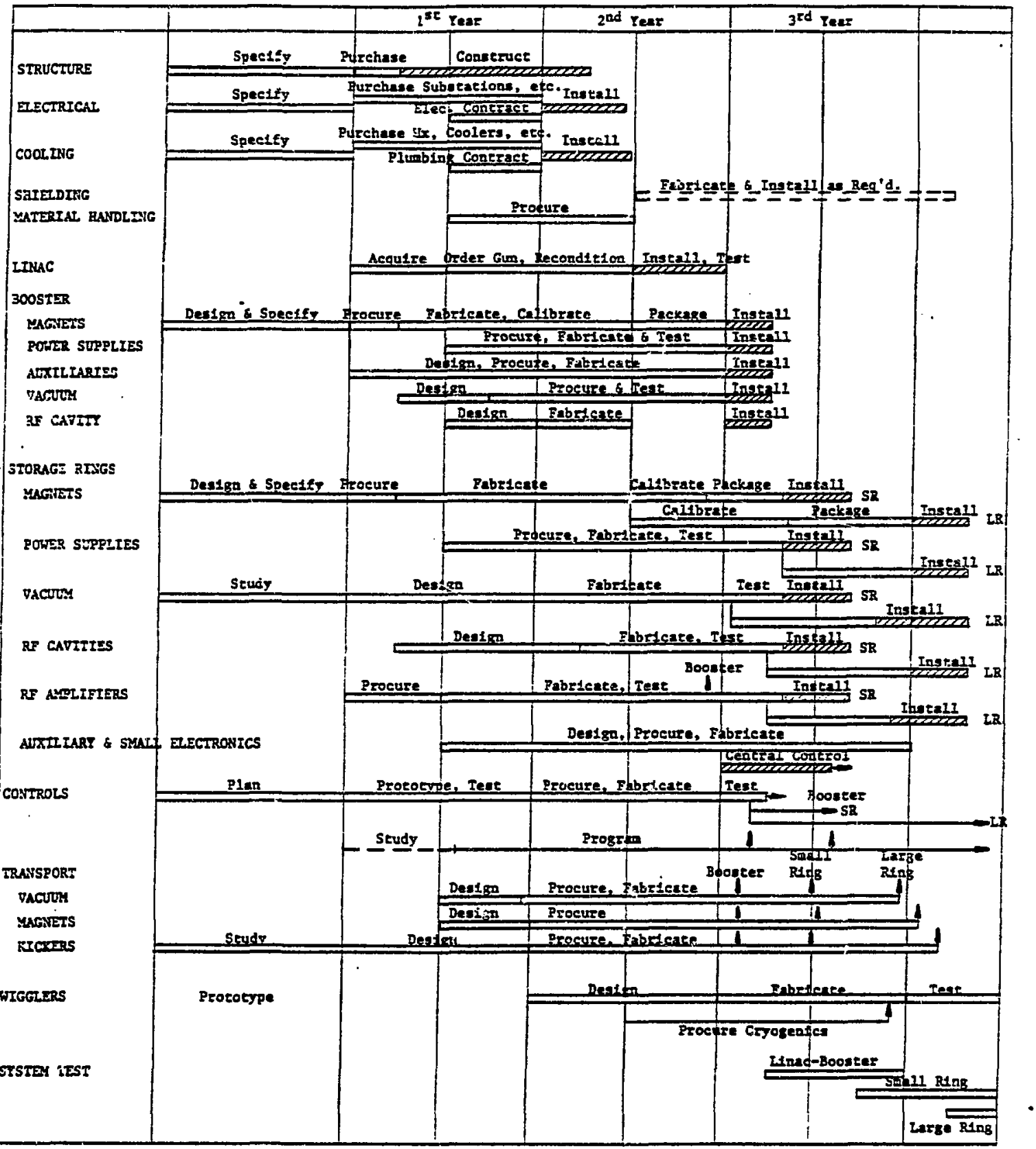

$L R$ - Large Ring
SR - Squil BAng 
amounts added as described below. The schedule of fiscal year obligations is shown in Table VI-4. An analysis of escalation and contingency amounts and the tetails of the total obligation flow are given in Table VI-5.

\section{Site, Buildings, and Utilities}

The building estimate is based on the "pre-engineered" type structure described in Section IV. The cost estimates are based on quotes from several fabricators; utflity estimates are based on Brookhaven experience. Appendix A contains the building and utilities engineering estimate work sheets.

\section{Storage Rings and Associated Equipment}

The estimates for components of the storage ring facility and its auxiliaries are based on Brookhaven's extenstve experience with similar components during the construction of two major accelerators. Where possible, estimates have been obtained from vendors.

3. Engineering, Design, and Inspection

This estimiste is based on the manpower schedule shown in Table VI-1 and on salary levels similar to those currently in use in Brookhaven's Accelerator Department, plus the Laboratory's current benefits costs. The total amounts to approximately $28 \%$ of construction costs.

\section{Contingencies}

Based on BNL's experfence and comparisons with other construction projects, contingencles are estimated at approximately:

$15 \%$ on bufldings and utilities

$23 \%$ on storage rings and associated equipment

$15 \%$ on ED \& I

\section{Escalation}

The escalation estimates are based on the assumption that "Inhouse" manpower costs will escalate at a $6 \%$ rate per year and that building 
and apparatus costs will rise at $8 \%$ per year. The escalation rates are applied to the anticipated obligation flow during each year, with the assumption that the project will be funded in FY 1978. Construction cost obligations are expected to be complete by the end of the first quarter of FY 1980. Detalls of the escalation calculations are shown In Table VI-5.

D. Research and Development

Th1s facllity w1ll serve a broad range of interest in various ERDA programs, as well as an extensive outside user community from university and Industrial laboratories. During the conceptual design phase, therefore, the project has profited greatly from efforts and technical data from various sources having long-term interests in the fac1lity. Continuing research and development work is expected to require operating expenditures as follows:

(In thousands)

$\begin{array}{ll}\text { FY } 1977 & \$ 500 \\ \text { FY } 1978 & 500 \\ \text { FY } 1979 & 500 \\ \text { FY } 1980 & 400 \\ \text { FY } 1981 & 400\end{array}$

The broad purpose of this effort inftially will be to follow up the work accomplished in conceptual design with more definitive examination of key components of the project so that detalled design and factlity construction can proceed as efficlently as posstble. This supporting activity will be of critical Importance, espectally in FY 1977 and FY 1978, for meeting the profect schedule. Work in the later stage will turn more to a program of development of new and sptcialized experimental apparatus for use on the bean lines. 


\section{E. Facility Operation}

Estimated annual costs associated with the operation of the proposed facility and the BNL in-house research "programs are summarized below. Amounts, shown In FY 1976 doilars, would cover the first year of operations with 10 eight-hour shifts per week scheduled for research durIng this Inftial perfod, plus an allowance for maintenance, machine phystcs, etc. It is planned to activate eight beam lines during this first operatIng year; a staged development for several subsequent years will involve activation of additional beam lines with an accompanying expansion of research programs. Over a five-year period, the budget is expected to rise by about $35 \%$ (In unescalated dollars), with a major portion of the increase Identified with the research budget component. Facility operating costs encompass those expenses for experimental area operations, equipment and machine development, and technical support for users, as well as costs assoclated directly with operation and maintenance of the machine 1tself. Capital costs are for equipment for both BNL and outside users. In order to have equipment ready for experiments at the elght beam Innes, this level of equipment funding will be required beginning two years prior to operation of the facility.

The cost estimate 1s given in FY 1976 dollars because of the uncertainties of inflation factors, espectally for electric power rates and prices of materials and supplies.

Cost in Thousands

Facility Operation $\$ 2,100$

Direct Manpower, including benefits (18 Professional, 24 Non-professional) $\$ 920$

Macerials, supplies, \& supporting services 305

Electric Power (15,000 MW hrs. \$26/MW hr.) 390

General and Administrative 
Cost in Thousands

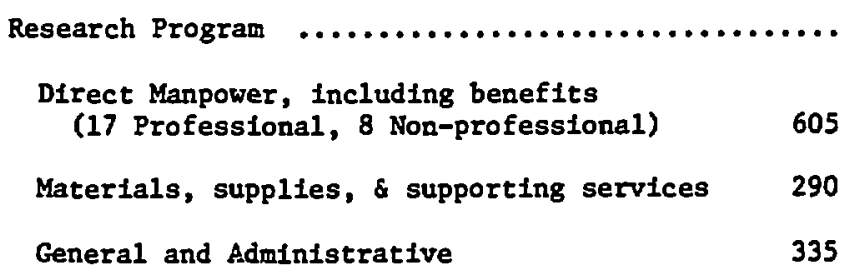

Total Operating Costs $\ldots \ldots \ldots \ldots \ldots \ldots \ldots \ldots \ldots \ldots \ldots$

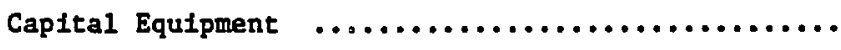

$\$ 1,230$

$\$ 3,330$

800

Research programs at the facility will encompass several scientific disciplines. It is anticlpated at this time that BNL utilization of the facility will include programs in Materials Sciences, Molecular Sciences, and Blomedical and Environmental Research in approximate percentages of 55,30 and 15 respectively. 
TABLE VI-1

\section{PERSONNEL EST IMATE}

(Man-Years)

Fiscal Year

$1978 \quad 1979 \quad \underline{1980} \quad 1981 \quad \underline{\text { Total }}$

\section{$E D \& I$}

Professional:

Fhysicists

Mechanical Engineers

$4.5 \quad 5$

2.5

Electrical Engineers

Vacuum Engineers

Control Engineers

Cryogenic Engineers

Civil Engineers

Administration

Total Professional

Non-Professional

Tota1 ED \& I

$\frac{15}{33} \quad \frac{24}{42} \quad \frac{24}{42} \quad \frac{7}{15} \quad \frac{70}{132}$

Assembly \& Machine Shop

4

26

34

13

77 
TABLE VI-2

SUMMARY COST ESTIMATE

(Thousands of Dollars)

Schedule A: Buildings and Jtilities $\ldots \ldots \ldots \ldots \ldots \ldots \ldots \ldots \ldots \ldots \ldots \ldots \ldots \ldots 2,945$

Improvement to land....................100

Utilities $\ldots \ldots \ldots \ldots \ldots \ldots \ldots \ldots \ldots \ldots \ldots . \ldots . \ldots . \ldots . \ldots 60$

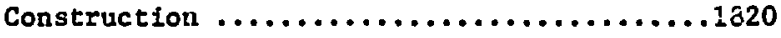

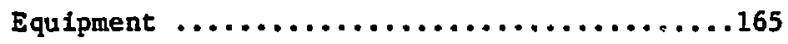

Schedule B: Storage Rings and Associated Equipment $\ldots \ldots \ldots \ldots \ldots \ldots \ldots \ldots, 030$

2-GeV Storage Ring.........................

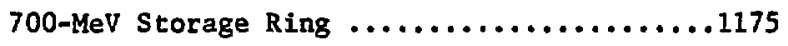

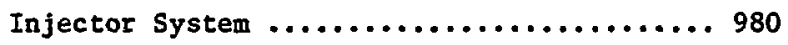

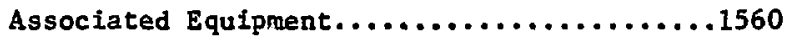

Experimental Equipment $\ldots \ldots \ldots \ldots \ldots \ldots \ldots \ldots 1800$

Schedule C: $E, D, \& I \ldots \ldots \ldots \ldots \ldots \ldots \ldots \ldots \ldots \ldots \ldots \ldots \ldots \ldots \ldots \ldots \ldots, 345$

Schedule $\mathrm{D}:$ Contingency $\ldots \ldots \ldots \ldots \ldots \ldots \ldots \ldots \ldots \ldots \ldots \ldots \ldots \ldots \ldots \ldots \ldots, \ldots \ldots, \ldots \ldots 0$

Schedule E: Escalation $\ldots \ldots \ldots \ldots \ldots \ldots \ldots \ldots \ldots \ldots \ldots \ldots \ldots \ldots \ldots \ldots \ldots \ldots, 480$

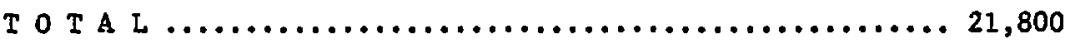




\section{TABLE VI-3}

\section{DETAILED COST ESTIMATE}

(In Thousands of Dollars)

Schedule A : Buildings and Utilities $\ldots \ldots \ldots \ldots \ldots \ldots \ldots \ldots \ldots \ldots \ldots \ldots \ldots 2,945$

1. Improvement to land (1)? .100

Preparation, grading, seeding

Paving, curbs

42

2. Utilities $(1)$ .860

Steam Service (L.S.)

Water Service (150 ft. ( $\$ 100)$

15

Sanitary Sewer (100 ft. e $\$ 50)$

Telephone (L.S.)

Storm Sewer $(1,800 \mathrm{ft}$. (a $\$ 25)$

Fire Alarm (L.S.)

Electric Utilities (L.S.)

Special Power (L.S.)

Trays and Special Conduit (L.S.)

Machine Cooiling (L.S.)

3. Construction (1) 1820

Main Building $(47,500 \mathrm{SF})$

1380

Offlce-Lab Wing $(6,250$ SF)

250

Mechanical Equipment touse

190

$$
(5,000 \mathrm{SF})
$$

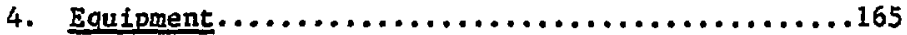

Laboratory Furniture

100

Materials Handling Equipment

65 
TABLE VI-3 (continued)

DETAILED COST ESTIMATE

(In Thousands of Dollars)

Schedule B: Storage Rings and Assoclated Equipment.............9,030

1. 2-GeV storage Ring.......................... 3515

Ring magnet system $\quad 1100$

Magnet Power 220

Vacuum System 1060

Transport, inflection \& bump coils 190

Low level electronics 210

Rf system $\quad 735$

2. 700-MeV Storage Ring....................1175

RIng magnet system 365

Magnet Power $\quad 80$

Vacuum System $\quad 330$

Transport, inflection \& bump coils 145

Low level electronics $\quad 140$

Rf system 215

3. Injector system....................980

Reconditioned linac 215

Ring magnet system 270

Magnet Power 115

Vacuum Systen 75

Transport and inflection 50

Low level electronics 90

Rf system $\quad 40$

Extraction $\quad 125$

4. Associated Equipment..................1560

Controls 620

wigglers and associated cryogenics 800

Shielding 140 


\section{$-72-$ \\ TABLE VI-3 (continued) \\ DETAILED COST ESTIMATE \\ (In Thousands of Dollars)}

5. Experimental Equipment................1800

Detectors \& spectrometers

Monochromators: normal and grazing incidence, and crystal

Experimental data acquisition and control

General optical equipment

Beamline and station mounts, vacuum equipment, and local shielding

Schedule C: Engineering, Design, and Inspection

132 man-years................................... 345

Schedule D: $\quad$ Contingency $\ldots \ldots \ldots \ldots \ldots \ldots \ldots \ldots \ldots \ldots \ldots \ldots \ldots, \ldots \ldots \ldots$

Bulldings and Utilitles a approx. $15 \% \quad 450$

Storage Rings and Auxiliaries

(c) approx. $23 \%$

$E, D, \& I$ @ approx. $15 \% \quad 500$

Schedule E: Escalation $\ldots \ldots \ldots \ldots \ldots \ldots \ldots \ldots \ldots \ldots \ldots \ldots \ldots \ldots \ldots \ldots \ldots .4, \ldots \ldots$

Buildings and Utilities 495

Storage Rings and Auxiltaries 2165

$E, D, \& I \quad 820$

т $о$ т А $2 \ldots \ldots \ldots \ldots \ldots \ldots \ldots \ldots \ldots \ldots \ldots \ldots \ldots \ldots \ldots \ldots, 21,800$

(1) See Appendix A, engineering estimate sheets, for details 
TABLE VI-4

Brookhaven National Laboratory

Project No. 78-CH-004

Syachrotron Radiation Research Facility

Schedule of Obligations (in Thousands)

EY1978 FY1979 EY1980 EY1981 Iotal Project

A. Englneering, Design \& Inspection Costs at 287. or Coustruction Costs

B. Construction Costs

1. Improverrents to Land

2. Accelerator Bullding

3. Attached Laboratory Hing

4. Mechanical Equipment Wing

5. Machine Cooling

6. Machine Power Facilities

7. Otilities

8. Special Facilfties

100

1,380

250

190

190

100

100

3,200

C. Standard Equioment

1. Laboratory Furniture and Equipment

2. Materials Eandling Equipment Sub-Total

D. Contingency on Above Obligations

E. Cost Escalation

Tctal Project Obligations Appropriations Requested
$\$ 850 \$ 1,060 \quad \$ 1,060 \$ 375$

$\$ 3,345$

$\$ 1,060 \quad \$ 1,060 \quad \$ 375$

$$
11,810
$$

100

1,380

250

190

430

200

230

130

3,675

1,930

225

9,030

165

100

100

65

65

$\begin{array}{rrrr}\overline{\$ 6,360} & \overline{\$ 5,115} & \overline{\$ 3,245} & \$ 500 \\ 765 & 1,200 & 965 & 70 \\ 885 & 1,315 & 1,050 & 230 \\ \overline{\$ 8,010} & \overline{\$ 7,630} & \overline{\$ 5,260} & \overline{\$ 900} \\ \$ 8,500 & \$ 8,500 & \$ 4,800 & \end{array}$

$\overline{\$ 15,320}$

3,000

3,480

$\$ 21,800$ 
TABLE VI-5

SYNCEROTRON RADLATION RESEARCH FACIIITY

ESCAIATION, CONTINGENCY, \& OBLIGATION FIOW ANALYSIS

( $\$$ in Thousands)

\section{FY197: FY1979 FY1980 FY1981 Tota1}

\section{Escalation Factors}

Manpower e 6\%/yr. from FY 1976
All other costs c $8 \% / y r$. from FY 1976 through 1st. qtr. of FY 1980
.12

.12

.26

.34

II. Base Estimate, Contingency, \& Escalation Analysis

A. Engineering, Design \& Inspection

Contingency \& $15 \%$

Sub-total

Escalation $6 \% / y x$.
Manpower Costs

\begin{tabular}{|c|c|c|c|c|c|}
\hline & $\begin{array}{l}850 \\
115\end{array}$ & $\begin{array}{r}1,060 \\
150\end{array}$ & $\begin{array}{r}1,060 \\
1 \in 5\end{array}$ & $\begin{array}{r}375 \\
70\end{array}$ & $\begin{array}{r}3,345 \\
500\end{array}$ \\
\hline & $\begin{array}{l}965 \\
120\end{array}$ & $\begin{array}{r}\$ 1,210 \\
230\end{array}$ & $\begin{array}{r}\$ 1,225 \\
230\end{array}$ & $\begin{array}{l}\$ 445 \\
150\end{array}$ & $\begin{array}{r}\$ 3,845 \\
820\end{array}$ \\
\hline
\end{tabular}

B. Construction \& Standard Equipment

1. Buildings, Utilities \& Standard Equipment

Contingency a $15 \%$

Sub-total

Escalation @ $8 \% / y r$.

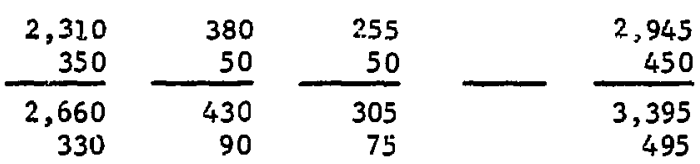

2. Special Facilities

Assembly \& Machine Shop Manpower All Other Costs

Sub-total Contingency a $23 \%$

Manpower Escalation e $6 \%$ Other Escalation e 8\%

\begin{tabular}{|c|c|c|c|c|}
\hline $\begin{array}{r}70 \\
3,130\end{array}$ & $\begin{array}{r}475 \\
3,200\end{array}$ & $\begin{array}{r}615 \\
1,31.5\end{array}$ & 225 & $\begin{array}{l}1,385 \\
7,645\end{array}$ \\
\hline $\begin{array}{r}3,200 \\
300 \\
10 \\
425\end{array}$ & $\begin{array}{r}3,675 \\
1,000 \\
95 \\
900\end{array}$ & $\begin{array}{r}1,930 \\
750 \\
165 \\
490\end{array}$ & 225 & $\begin{array}{r}9,030 \\
2,050 \\
350 \\
1,815\end{array}$ \\
\hline
\end{tabular}

III. Obligation Flow

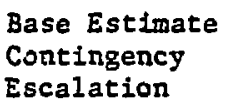

Total Obligations

$$
\begin{array}{rrrrr}
6,360 & 5,115 & 3,245 & 600 & 15,320 \\
765 & 1,200 & 965 & 70 & 3,000 \\
885 & 1,315 & 1,050 & 230 & 3,480 \\
\cline { 2 - 2 } & \$ \$ 7,630 & \frac{\$ 5,260}{\$ 900} & \frac{\$ 21,800}{\$ 2}
\end{array}
$$


VII. OTHER CONSIDERATIONS

A. Codes, Standards, Quality Assurance

Codes, standards, and quality assurance as applied to the proposed Synchrotron Radlation Research Facility will fall into two major categories: a) buildings and site, and b) the storage rings, linac, booster, and support equipment.

\section{Buildings and site}

Construction will conform to applicable standards and codes set forth in ERDA Ganeral Design Criteria, Appendix 6301. Safety of personnel during construction is covered by Part 1910 (General Industry Safety and Healtin Regulations) and Part 1926 (Construction Safety and Heal th Regulations) of the Occupational Safety and Health Act, by ERDA Manual Chapter 0550, Operational Safety Standards, and by the BNL Safety Manual.

The model codes in use at BNL Include the Oniform Building Code (International Conference of Building Officials), the National Electric Code (NFPA), and the National P1umbing Code (ASME). Codes of the American Sociecy of Heating, Refrigerating, and Air-Conditioning Engineers (ASHRAE), the Air-Conditioning and Refrigeration Institute (ARI), and the Air-Moving and Conditioning Association (AMCA) will form an integral part of the mechnical specifications. The National Fire Codes (NFPA) are the guidelines for fire protection. Included in the aforementioned documents are material and test standards of the several accredited organizations. All mandated codes and standardis will be adhered to and careful attention will be given to the use of voluntary standards as a means of efficiently communicating design needs and implementing quality control. There are almost 600 construction-reiated standards and guides prepared or distributed by the American National Standards Institute. Wharever possible, these will be utilized. The "Recommended Design Practice Manual" oi the 
Metal Building Manufacturers Assuciation will supplement the code in our building design. During the course of building design the staff will follow work now underway at the National Bureau of Standards, the Federal Energy Administration, ASHRAE and elsewhere so that recommendations for energy conservation can be incorporated.

Quality assurance for the building and site will be based on the following:

a) Understanding of site conditions. BNL will verify if soil mechanics properties at the site of the proposed building are similar to those at AGS where extensive data exist.

b) Proper design and placement of slab. BNL staff members will eitier design the slab, check the calculations of the building vendor if it is to be part of his contract, or hire a structural consultant for this purpose. The project staff will either prepare the specification or participate in the approval process. Records will be kept of material and mix certifications, strength tests, etc. BNL will have field personnel check the site before, during and after placement of concrete. The Laboratory will reserve the right to stop work if the contractor does not follow specifications.

c) Collaboration with pre-engineered metal bullding fabricator. BNL will determine the building size, Minimum headroom, points of interference between equipment and structural members and locetion of doors, windows, and other architectural features. The Laboratory staff will also prepare performance specifications for HVAC, lighting, toilets, etc. The vendor will be responsible for cose compliance. Prior tc construction the veudor will submit the following documents for BNL approval:

1) Architectural drawings, including a list of materials of construction. 
if) Structural calculations.

lii) Specifications to subcontractors and equípment suppliers.

iv) HVAC calculations.

v) Lighting and plunbing layouts.

These documents will become part of the job file as will asbuilt drawings, parts lists and maintenance manuals.

BNL engineers will coordinate the work of the building con-

tractor with that of the excavation and slab subcontractors and those providing site utilities, roads and curbs, power and cooling water. The project staff will also provide field supervision and inspection.

\section{Storage Rings, Linac, Booster, Support Equipment}

The design, procurement, fabrication and placement of the myriad components that comprise the storage rings and experimental beam lines are so specialized as to be beyond much of the existing consensustype standards. Extremely high levels of quality control are necessary and will be exercised because of required performance of many systems, coupled with their high initial cost and the cost of unplanned shutdowns. The Project staff's approach to quality control will be made easier by Brookhaven's single responsibiltty for design, procurement, and installation of the rings and ancilliary equipment. The Laboratory's long history of accelerator design, construction and operation has resulted in the compilation of a considerable body of specifications and design guides. Many of these can be readily appiled to the proposed rings.

Quality control during design and development will include scheduling of design activities and assignment of responsibilities among the staff. A design and drawing file will be maintained for calculations and up-to-date prints. A system of design review will be undertaken so that criteria and alternate approaches can be evaluated for cost effective- 
ness and confirmation to project objectives. Specifications will be prepared in conjunction with drawings that identify materials, describe manufacturing processes when necessary, and define the basis of acceptance and methods of testing. Wherever possible recognized standards of the ANSI, ASTM, AWS, ASME and others will be incorporated.

$$
\text { Quality control will be an integral part of procurement }
$$

and fabrication procedures. Contract documents, including purchase orders, change orders, etc. will clearly identify the level of quality assurance expected from the vendor. This may include the submittal of one or more of the following documents:
a) material certification and identification
b) inspection and test reports
c) process control data
d) nondestructive examination
e) as-built drawings
f) cleaning, packaging and shipping procedures

Vendors will be chosen from a list of qualified bidders maintained by the Purchasing Division. Members of the Project Staff will have access to the vendor's plant during manufacture to inspect components or witness tests

Qua1ity assurance requirements for Installation will begin with a procedure outlining the sequence of work and division of responsibilities for staging, handling, setting, aligning, cleaning, testing, inspecting and reworking subassemblies and systems. Complete records will be maintained for major systems listing final inspection measurements, reyairs, as-built dimensions, etc. 
Procedures will also be established for pre-operation testing and records kept of performance and modifications during these tests. Prior to full operation of the synchrotron, a maintenance program will be initiated. The program will be designed to ensure that project requirements are met by planned replacement of some components and overhaul maintenance of others. The maintenance policy objectives will be defined, spare parts Identified, procured and stored, and a recormended timetable established for inspection and implementation.

\section{B. Methods of Per formance}

It is proposed that the engineering, design and inspection of the building and utilities, as well as the award of competitively obtained lump-sum contract(s) for the construction work be done by Brookhaven National Laboratory. This appears to be the most practical and desirable method of accomplishment in view of the controls that Brookhaven must exercise in design and construction in order to minimize interferences with other programs at the Laboratory, and to assure that the requirements of ERDA with respect to safety and fire prevention are met. Brookhaven has the resources and experience in engineering, design, inspection, and contract management required for developing detalled specifications for erecting the pre-engineered steel bullding and installing utilities. Construction and procurement will be accomplished by fixed price purchases and contracts awarded on the basis of competitive bidding. Enginzering design of inajor components (magnet sectors, main vacuum chamber, if cavities, etc.) will be performed by Brookhaven. Fabrication of these elements, as well as the provision of magnet and if power supplies, cryogenics, control equipment, etc. where possible will be by comercial vendors on the basis of fixed price contracts awarded on the basis of competittve bidding. Assembly and testing will be performed by Brookhaven. 


\section{c. Environmental Protection Requirements}

As presently conceived, construction and operation of this project will not generate any significant air or water pollutants except sanitary wastes which will be discharged into existinf sawers connected to adequate treatment facilities or in areas of low population density, occupled intermittently, into septic tanks with leaci:ing fields. The estimated cost of the profect includes costs of those measures necessary to assure compliance with Executive Order 11752.

An environmental analysis is presently being prepared and will be available shortly.

\section{Health and Safety}

The principal health and safety risks associated with this facility are similar to problems that have been dealt with successfully at other BNL facilities. Adequate shielding w111 be established to limit the dose equivalent rates to $0.25 \mathrm{mrem} / \mathrm{hr}$ in accessible areas during normel machine operation. Additlonally, the shielding will be sufficient to limit the total dose equivalent rates to 100 rmen or less in the event of complete beam loss at a single point. Induced radioactivity an mashe components will not be a major problem, Electrical hazards associated with the $R-F$ and other high voltage components will be protected within enclosure spaces and interlocked with both electrical circuits and key systems. Any storage capacitors w111 be equipped with automatic mechanical discharge cevices. Fire detectors and a sprinkler system will be installed throughout the facility. Exits from the building will be in accordance with the Iife safety code. 
APPENDIX A

BUILDING \& UTILITIES ENGINEERING ESTIMATE WORK SHEETS 
BUILDING SUMMARY OF J. H. LANCASTER'S ESTIMATES

$\star$

\begin{tabular}{|c|c|c|c|}
\hline & \multicolumn{3}{|c|}{ \$ in Thousands } \\
\hline & $\begin{array}{l}\text { Accel. } \\
\text { Bldg. }\end{array}$ & $\begin{array}{r}\text { Office \& } \\
\text { Lab Wing } \\
\end{array}$ & $\begin{array}{l}\text { Kech. Equip. } \\
\text { Wing } \\
\end{array}$ \\
\hline Foundations & 31 & 6 & 6 \\
\hline Slab & 211 & 9 & 10 \\
\hline Structure & $475^{\star}$ & $63^{*}$ & 40 \\
\hline Doors, etc. & 11 & 4 & 5 \\
\hline Interior Finish & 12 & 27 & 2 \\
\hline Electric & 167 & 20 & 17 \\
\hline HVAC & 355 & 45 & 25 \\
\hline Sprinkler & 94 & 20 & 15 \\
\hline Tollezs, etc. & $13^{\star}$ & 29 & - \\
\hline Floor Drains, etc. & - & $27^{\star}$ & 40 \\
\hline Steam Pit & - & - & 10 \\
\hline Spec. Foundations & - & - & 18 \\
\hline Total & 1370 & 250 & 188 \\
\hline Sq. Fe. & 47,500 & 6,250 & 5,000 \\
\hline $\operatorname{Cost} / \mathrm{Sq}$. Ft. & 28.84 & 40.00 & 37.60 \\
\hline Use & $\begin{array}{r}29.00 \\
\times 47,500 \\
\end{array}$ & $\begin{array}{r}40.00 \\
\times 6,250 \\
\end{array}$ & $\begin{array}{r}38.00 \\
\times 5,000 \\
\end{array}$ \\
\hline & $1,377.5$ & 250 & 190 \\
\hline Budget Numbers & 1,380 & 250 & 190 \\
\hline
\end{tabular}


APPENDIX A - 2

SITE KMOKK

Stritizing

Clearing

Eack fill $340^{\prime} \times 360^{\circ} \times 1^{\prime} \div 27=4600$ cr e $2.00 / \mathrm{yy}$ $340^{\circ} \times 360^{\circ} \div 43.560=3$ ACre: $C^{1} 1000 / \mathrm{Ac}$ $300^{\circ} \times 300^{\circ} \times 3^{\circ}+27=10,000 \mathrm{ct} e^{5} 2.50 / \mathrm{cT}$

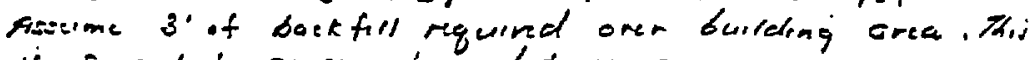
is somewhat conservating but necerseny

Compect Bectefir $10000 \mathrm{ey} C * 1,00 \mathrm{cy}$

Compect to density equal or qreater then that of origional soil

Pearee Topsor, $50^{\prime} \times\left(300^{\prime 2}+300+300+300\right) \times 1 \frac{1}{2} \times \frac{1}{27}=3400 \mathrm{CrC} 2.00$

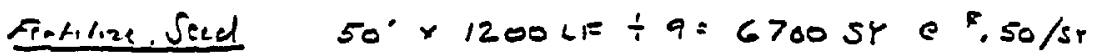

Parement west $45 \times 80=3600$

$$
\begin{aligned}
25 \times(55+40+40) & =3375 \\
\text { Nuth } 25 \times 100 & =2500 \\
\text { South } 25 \times 90 \times 2 & =4500 \\
\text { Eart } 275 \times 65 & =\frac{17875}{31850 \div 9}=3600540^{5} 85
\end{aligned}
$$

Side walle $\left(40^{90} \div 50\right) \times 6^{\circ}=5405 \% \times 1.20 / 5 F=.640^{*}$

Gubirg an Main entrence only

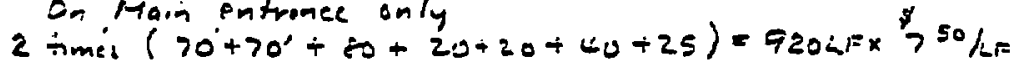

Serinte Fill bermen Cuts on rechaology

$$
140^{\circ} \times 12^{\circ}=16 \pm 051^{\circ} \times 1.20 / 5=
$$

\$ $k$

?

3

25

10

7

4

31

7

2

97 
APPENDIX $A-3$

SRRF Estimait Eizzith

UTILITIES

steom

Connest to Mombole NE Cormen of Protheren ead Tranology

Menioio Piping

Cnelcoground Run

including trenching

Steam Rechetion Steition on Ruideling Sug do.00

hater
Conncet to Tiechnology. Strett?

Cut into exosting main, valve $31,000+\$ 1000$

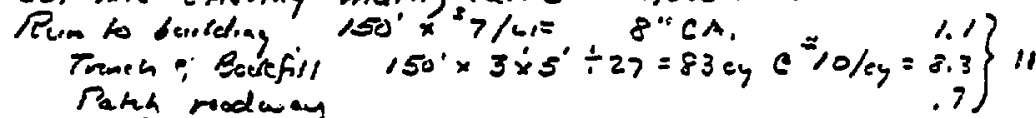

valving for Spriatier Sys km

2

2 J.t. Lunchite.

$\$ k$

$\div \geq$

30

8

15

Suitom Sewer Conncet to M.A. on Techmoloyy Strut $100 \alpha F \times \div 0 / 41=1,000$

$100<1=3 \times 5 \div 27=56$ ey 0 ex/oy

clean out Mankole ekeer line

Telephone No infirmation

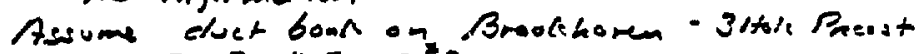
$100<r$ e $4.50=7.10$

$160 \times 3 \times 5 \div 27=100 \times y \times 10 / 6 \mathrm{~T}$

Pael ete insice bistering

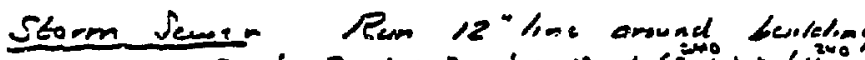

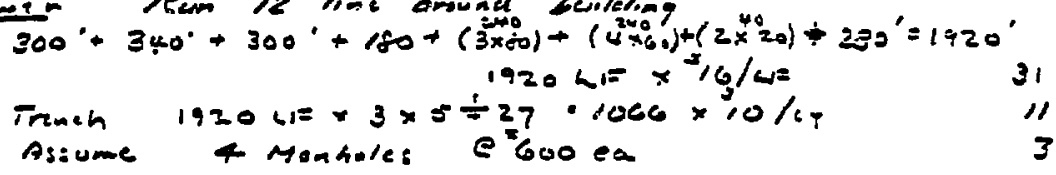

45

3

4

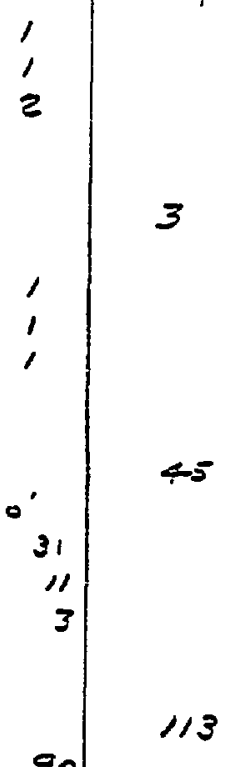

Eleeime Tap a pos Feceler.

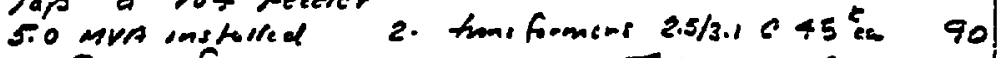

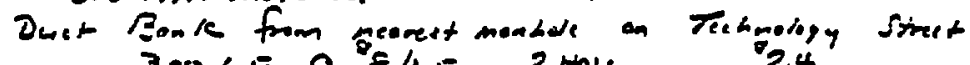

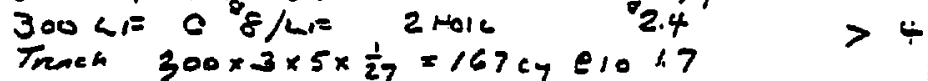

Cable $\quad 60061=+400+300^{\circ}=1300<, F=6 / 5 / 6 \quad 17$

Asrume one Montole a sou ca

2

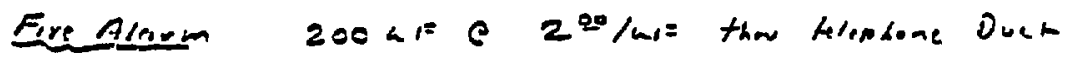


APPENDIX A -4

SRET Fimaie E/zZiro S.1t. Lun a. : thr

Dullo ne

Eureling; Fundater:

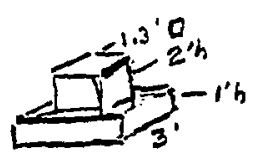

Volume

$$
\begin{array}{rl|l}
1.3 \times 1.3 \times 2 & =3.4 \\
3.0 \times 3.0 \times 1 & =\frac{9.0}{12.4} \\
\text { Volume } & =\frac{1}{10} \\
& =.4654
\end{array}
$$

Ainc. Buttom $25 x=0=1250 \mathrm{sF} \times 30^{*} / \mathrm{sF}=37500^{\circ} \div 500 \% / \mathrm{s}=7.5 \mathrm{sF}$

Number of Foutiags $12+12+12+11+11=50$

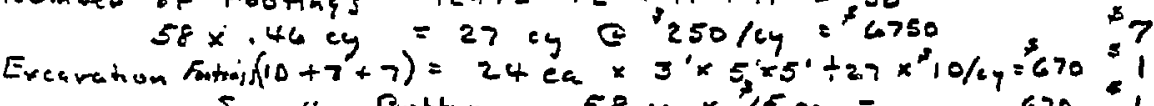

Erude Beam

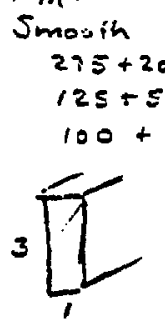

58 ce $x \geqslant$ sea $=$

$670 \quad 1$

$(18,5)$

$(2.4)$

$$
\begin{aligned}
& 3 \mathrm{CF} / F \\
& 1325 \times 3 \times \frac{1}{27}=148 \mathrm{cy} \times 175 / \mathrm{cr}=
\end{aligned}
$$

Opifiser woug Cols

Ereorinon Grods Reem

$$
6 \text { footing }=\times .46 \mathrm{cy}=3 \mathrm{cy} \times 1250 \% 750
$$

5

$1325 \times 3 \times 3 \div 29=442 \times 10 / 0 y=4420$

5 ine rocelffill

Berdeting $\frac{5 \% 6 s}{\text { Compes }}$

tomporion and Rockfir is in Sik work

47,500 5F 12 "thick $w /$ Heary

Highwsy reest at top and botrom

$47.500 \times 1 \times \frac{1}{27}=1760 \mathrm{cy} \times F / 20 / \mathrm{cr}=211,000$

Concule $12 " 5 / 26 \quad 220 / \mathrm{s}=27=60 / \mathrm{cr}$

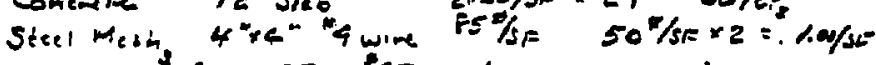

Frest $21,00 \times 27=27.00 / 164$

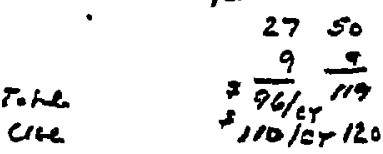

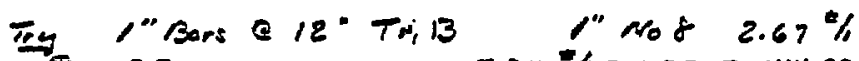

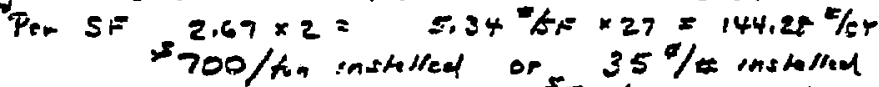
or $550 \%$ tom inshilled

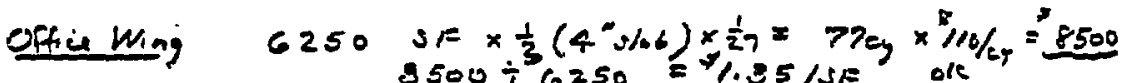
9

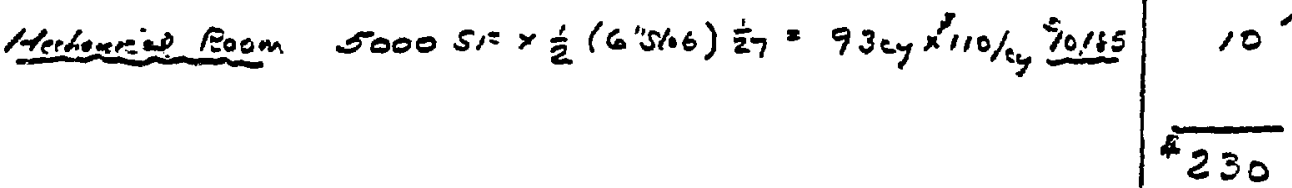


APPENDIX A - $\mathrm{J}$

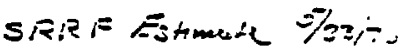

BuILOINE DNLancodir

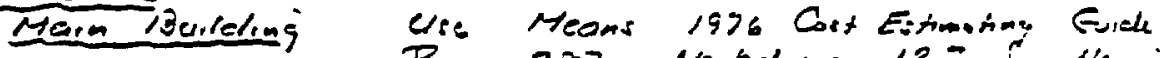

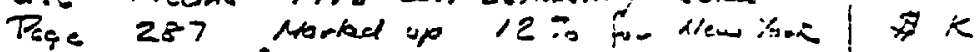
ond $18 \%$ for $0.4 \%$ Profit $1 \times 1.18 \times 1.12=1.23$ Sam 2o'herints.

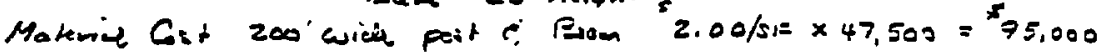
Fretion cort Paf Ef frome os $\times 47.500=38.000$ Wall $20 \times 950 L F=1900051=\times .45$

For New York $\times 1,32$

Coet per Sgure Foot

Cust to Lemer 19,000 sis e 1.00/st

Try Ore-lll Tokel Got given on Page 287

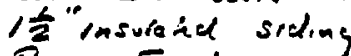

Ponel Fimesh $19,000 \mathrm{~s} F \mathrm{C} 18 \% \mathrm{~s}=$

$\frac{8,600}{141,600}$

$7,86,900$

$\times 3.93 / 5 \%$

19,100

$.40 / 5:=-$

$47,5605=$

130,600

19,000

$\frac{3.400}{153.000}$

202,000

IVot:E Niee Sheets

For Mew Yo.te $\times 1.32$

Clise Medion o 8.00/5F

Cost per sguve foct

4.25

$8.00 / 5=\times 47,500=380,000$

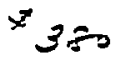

Interoon Finivit Paint floor 2 Couts Floor Fnemel

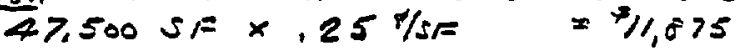

12

No foush pointing on Structural Stecl - Loner Po-forified

Ocerheod Doors Sted Rolleng wopcoing

4 each - $12 \times 14$ oit Doom e 32000 ea

8 each $5 \times 7$ 0oort $C^{3} 350=0$

8

3

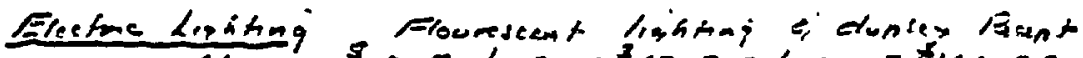

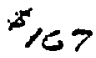

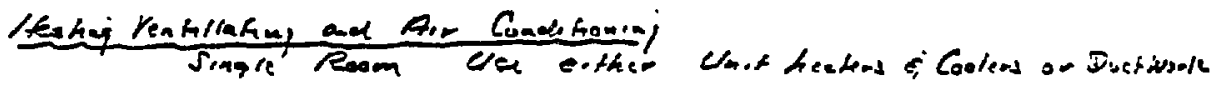

$$
\text { Cis } 7.50 / 5 F \times 47,5005 F=356,250
$$

355

$\frac{\text { Serinkler Sustem }}{\text { Open }}$

cla splos/si= $x<7.50051==83,125$

34
50

Total ineludiag Conemt S/o6

$3,23 i$

Cust per Spure fout

$525.92 /:=$ 
APPENDIX A - 6

SRRF Estimate Fisite D.Himenuster

Try HuAC tine PEP way

$$
47,500 \mathrm{SF} \div 306 \mathrm{sF} / \mathrm{TH}=158 \text { tons }
$$

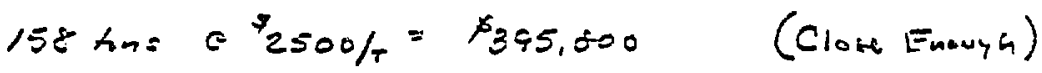

a) $\angle A$

OrFicieA Winc

Strutum

$12 \operatorname{tEan} \operatorname{herght}$
$625051=e^{5.00 / 51}=5.50,000$

$\$ K$

Intrion Fenesi Floor $5000 \mathrm{~s}=$ Trle Floor P\$75

1250 IF Pant c..25

3750

50

$\times 4000$

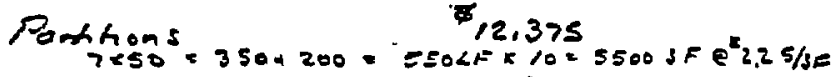

13

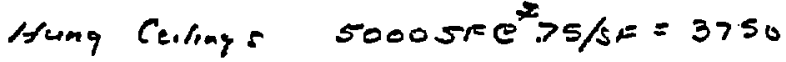

Pantiag Porthonis H,010 si= $x^{5} .40 / 5 \%=4400$

Door: Sen $20 e^{5} 200$ sa

Hindurs: Say 8 e 100 ea

$=4000$

4

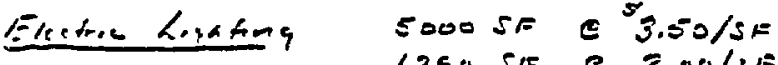

1250510 o $2.00 / 31=$

17500

Eo -

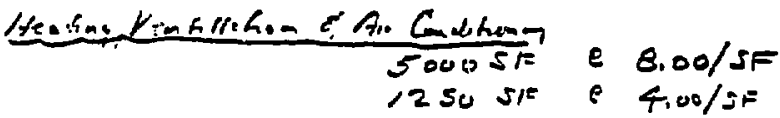

40,000

2500

800

5,000

Serecer System

$625051=e^{2} 2.25 / \mathrm{s}==14062$

Kalus et

Toilets, Firtures $20+2 \omega s+2 L>10$ ea $O^{2} 2,00 \%$ compes 20

Acessomed $2 \omega 0+26500$

Panhon: $5 e 300$

Dnotion Fonder $\quad 3 e^{600}=1800$

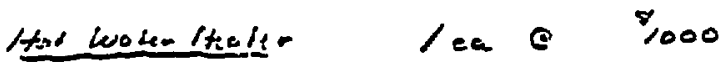

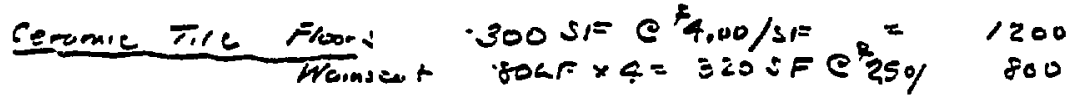

Total Imetudiug Comere Stes

1

2

$\frac{15}{5}$

23

$-5$

5

4

,

'

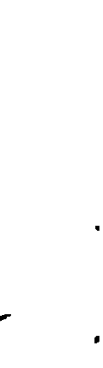


APEENDIX A -7

SRRF Estimath Fi23iT=

Mrentarmenal Equpmiant Boom

Strueters 20' Save techer

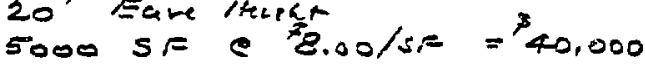

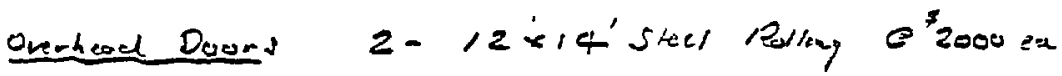

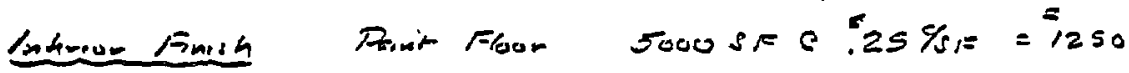

Electere Lithing sooost e s $3.50 / 51= \pm 17,500$

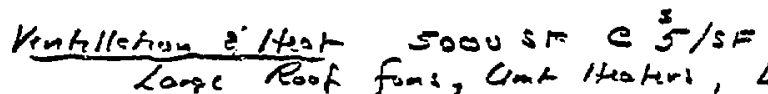

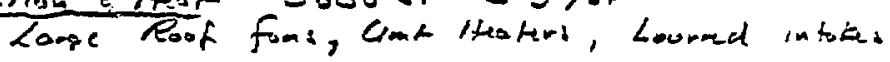

Mon Doors 2 each e 350 en w/houlumen $=700$

Spunieter System 5000 sf e $\$ 1,75 / 3:=-2750$ rolve: Ete

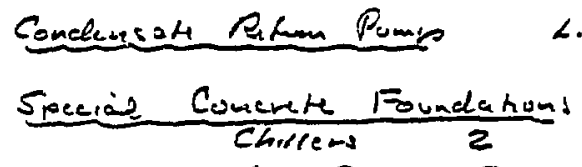

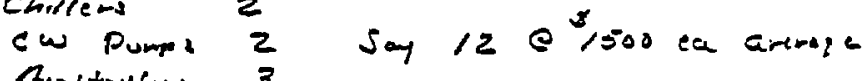
A. iturelar 3
it Comp 2

Totel incrocing 5 tor

Cun per SF

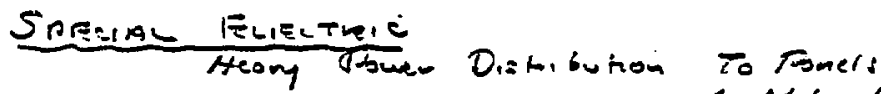

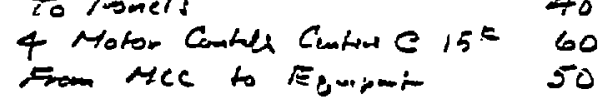

$\frac{\text { Special Plumbinie: }}{\text { Ploor droins }}$

in Mechourcel Room

Drain to Stom flum

40

$=0$ 
APPENDIX A- 8

SRRI= Finmais S/2zi-io

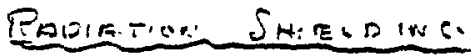

$$
\begin{aligned}
& \text { Moin Fing a cer } \\
& \text { Boothr zem } \\
& 4504 F \\
& \text { 7earee expm } \\
& 124 L= \\
& 150 \mathrm{LF}
\end{aligned}
$$

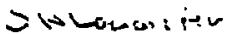

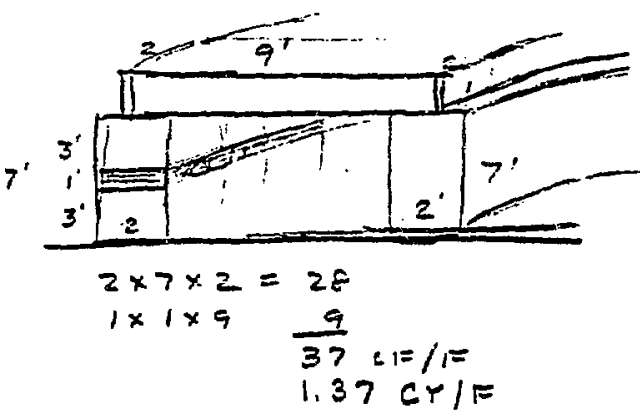

Harer Ping

$$
450 \angle 1=\times 1.3764 / 6,=616.5 \text { cy } 0+160 \% y=98,650
$$

$300-k r$

Not Inclucled

$$
124<1=\times 1.37 \mathrm{cr} / \mathrm{LP}=169.5 \mathrm{cy}=160 \mathrm{sy}=27.170
$$

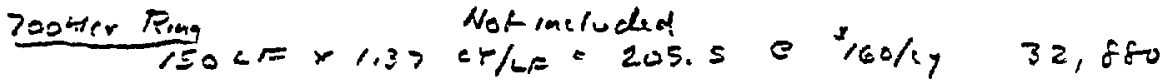

hitar Speciel Lerust and Finfui

Eram. Dump

Source laterb Findivion Formely with trhite Comsinction Now with Brotherton Constructom Corp les firlontic struet Hakensack, N.V. 07601

$$
\text { Tel } 201-487-8,48
$$

He said a good sitimin for the bere biestes would be $\$ / 20 / \mathrm{cy}$ to which hos to 4 \% $120 / 04$ aded the sleeres, lofting attichoms parmting, delivery and instiliodon, foler

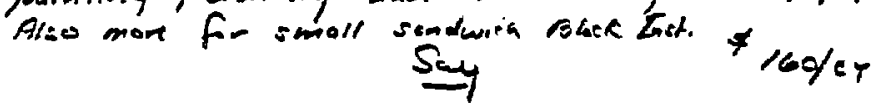

Ne comer Prathon 
APPENDIX A -9

SRIRF Estimaie $5 / 24 / 50$ owhoncas ter

Sprinker Systions

$$
\begin{aligned}
& \text { Armeo } \\
& \text { Stran-Sted } \\
& \text { Buter }
\end{aligned}
$$

No Price

$7.00 / 5 /=$

$3 / .00 / 51=$

than Pan

offic

$81.25 / 58$

Try Means $B_{3} 200$

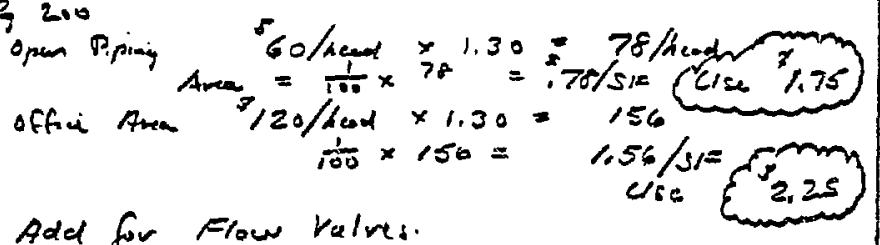

Add for Flow valves.

$k \stackrel{\nabla}{*}$

Machine Coolray

430

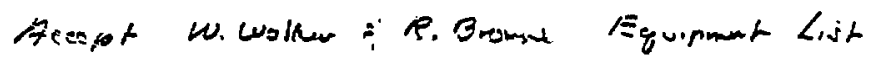

Main Hadews

Manáfolds ititar $\frac{450 L}{50^{\circ}}=9$ is

raster $\quad \frac{1246}{50}=3 \quad 4>1807000$

Toomer $\frac{150}{50}=3$

Instectection

100200

Instollation of Equpmint $20 \%, 131$

Evap for Sices $4 / c$

Mesc Controls, Elee thate-up ete

$$
\begin{gathered}
131 \\
150^{k} \\
18 \\
4 \\
30 \\
50 \\
\frac{50}{433}
\end{gathered}
$$

Bllawane for Trays, special conduit et at Celing level 'for distutution of recondory wiring,

$=0$ 
APPENDTE $A-10$

SRRF Estimo:-1 \%/2-176

S.WLUarth-

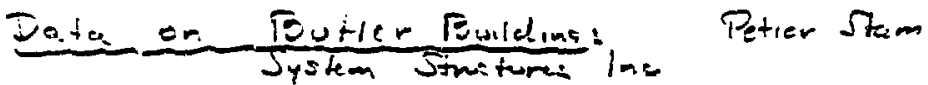

HA7- 9600

$I \operatorname{hod}$

tre misocel on dimensions end Stam had a slighty laper burting them.

Lendmork Builami

Seamed Roof comuthleate

50' bay spaeing $\times 30^{\prime}$ bay

L. Shope

rietianical Space office Space

fil $24^{\prime}$ Fore height eren offic

$$
\begin{aligned}
& 200 \times 270=5400051= \\
& 100 \times 30=3000 \\
& 50 \times 70=4500
\end{aligned}
$$

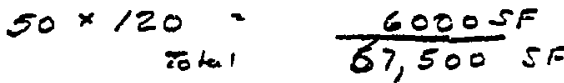

Monopanel cesced throuptout - two 26 ga stell sheets with 2 " fibmgli: insulesion between $U=.15 \mathrm{mall}$ Cost $2.50 / \mathrm{s}=$ instolled This elimineter the enteror girts

Umean contractor: - Dami - Bacon wafel

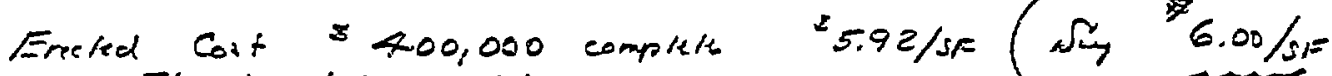
Thri is ibell complete

Rouf 2 "insulition 26 Ea Sheet $0=.12$

Roof Locking Atiph Bay $30^{*} \mathrm{LC}-20^{\circ}$ wind

$$
\text { office } 50 \text { rea- } 20 \text { wind }
$$

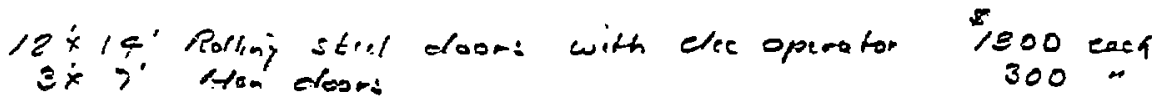

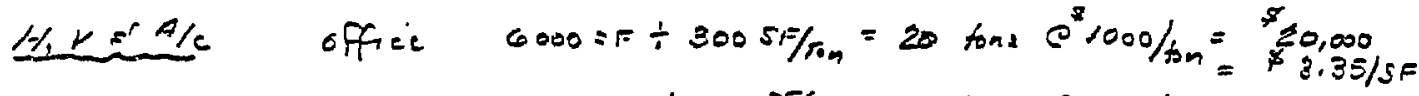

Hiqh Boy $5700051=2505 \%$ \%on $=228 \mathrm{Ama} C 1000 / \mathrm{Ton}=228,000$

$={ }^{\circ}, 00 / \mathrm{sF}$

Electree liakting office $2,00 / 51=$

$$
\text { that Bay } F / .25 / 5 F
$$

P/un61ag

toov per froture unit ineswad dmanose

Sereteres:

$$
\begin{aligned}
57,000 \div 100 \mathrm{5r} / \mathrm{hed}=570 \mathrm{HAads} \times \mathrm{F} 5 / \mathrm{h}=\frac{8}{48,450}=.85 / \mathrm{s}
\end{aligned}
$$

He reommencled $\$ 1.25 / \mathrm{s} /=$ for offic

$1.00 \%$ site for Higa Boy Areas

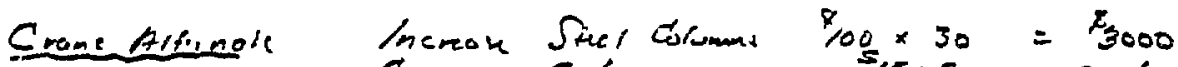

Crones 5 fon $5 / 5-20,000$ each

Crome Runercys

5-6000 eath 
APPEND IX A -11

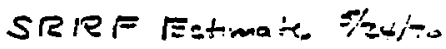
St Lanceiter

Data Stran Steel 1 Building

Setartet

Mr Dorid Mills

teiphone $751-0653$

Burrofinj climentrous as shown on Sheet Insciration 3 "thile stondard on. walls s' pof $U=.10$ Walle 20 ga shees wifh limer to ' 12 'I theriet

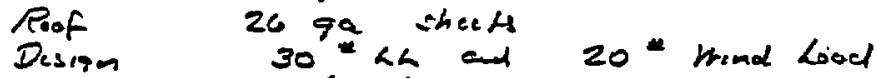

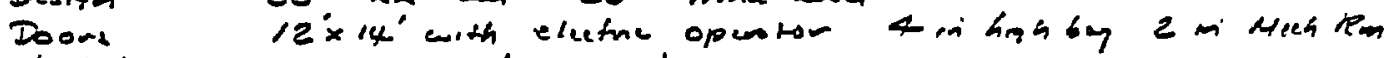
luckode, gutters and downspouts

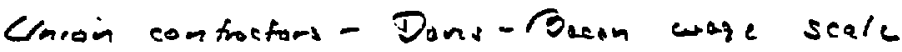

Cost Basic Burlding

Electice IAVAC

Turnetrey tothe

Sprenkrer System

Plombing Fxture
A. OO KF

$4.00 / 11=$

$\frac{3.00 \%: 11=}{15.00}$

Whe 75 per head

1.00 per SF

3 350/enit Non-Union

"E.00/sF

1000 Union

Brose Crone - No Price

Burdeng wise only hold one - I ecordunt ger a rationa! expracietion of thes'. 
APPENDIX A -12

SRRF Extimatio Ftzitic

SWlamanith

Deta fom Armeo Stee Company

Mr Sterzei HUE- 2280

Building size as shown en Sheet no

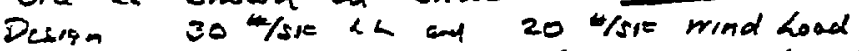

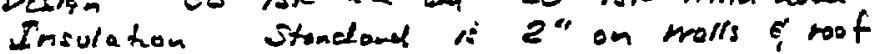

$\cos +.35 / 51$

Bays are $24^{\prime}$ and $28^{\prime}$ stondord

trall: 2699 wall coverng

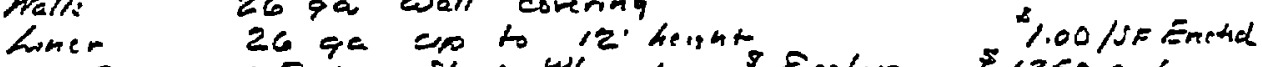

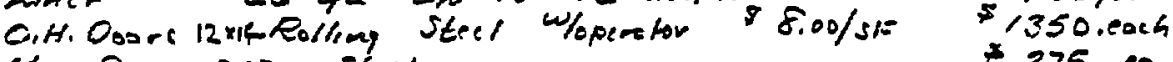

Hom Doors $3 \times 7$ Stell

- 275. ea

Eutters \&: Eownspouth $\quad x_{3.50 \%=}$

3000 for Burlstir:

Coste ifructure completely Materail $\$ 6.00 / \mathrm{s}=$

Erection $\quad \frac{2.50 / \mathrm{s} F}{8.50}$

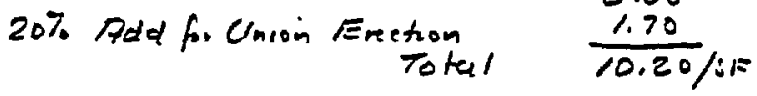

Lakting F'Aixtures controusu

HVAC

(2)

$7.00 / \mathrm{s}=$
$5.00 / \mathrm{s}=$

Crone Claderstung 5 ton $\$ 12,000$ each

Sfecl needs streugthenereng adoded 